4

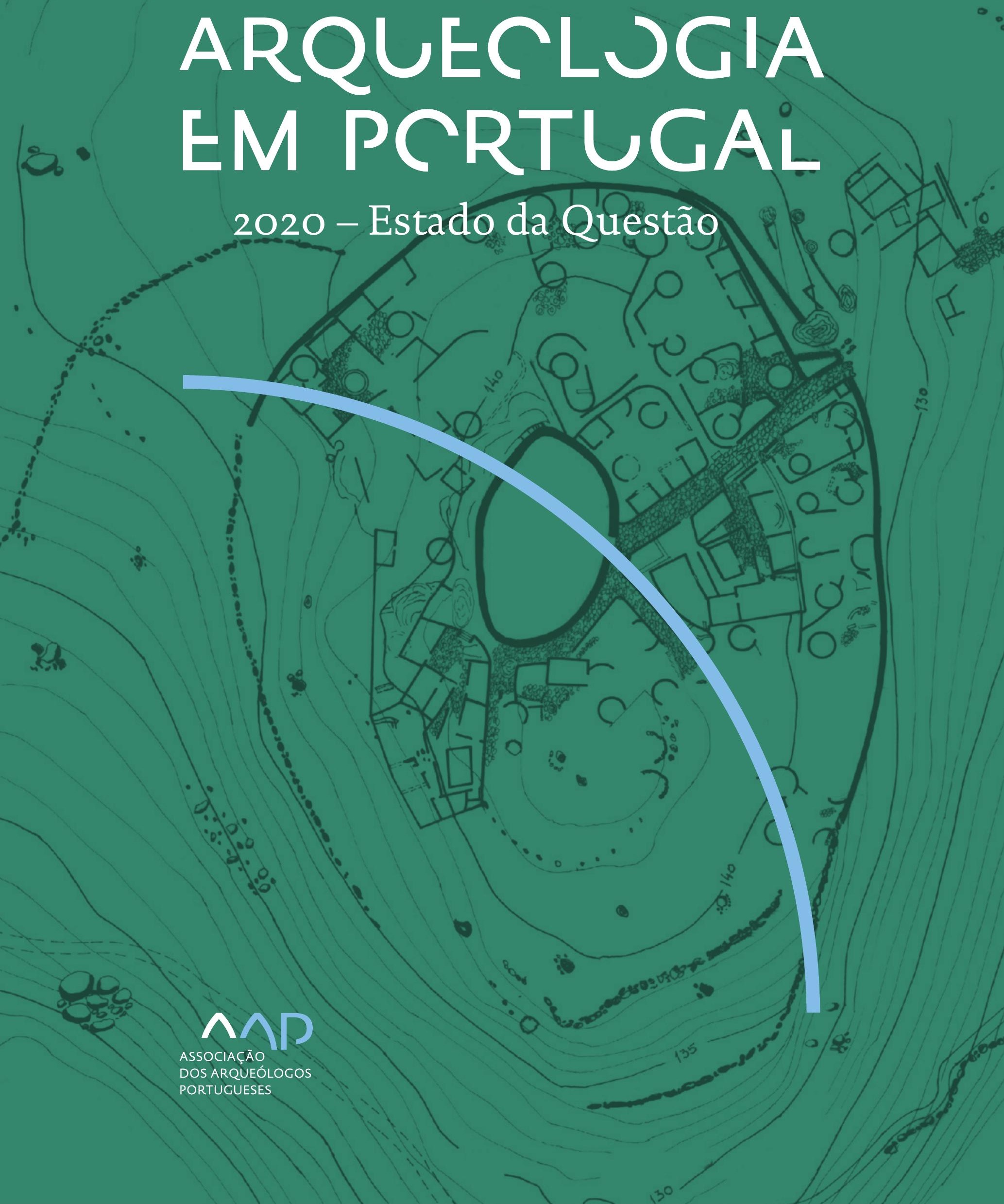


Coordenação editorial: José Morais Arnaud, César Neves e Andrea Martins Design gráfico: Flatland Design

AAP - ISBN: 978-972-9451-89-8

CITCEM - ISBN: 978-989-8970-25-1

Associação dos Arqueólogos Portugueses e CITCEM

Lisboa, 2020

O conteúdo dos artigos é da inteira responsabilidade dos autores. Sendo assim a Associação dos Arqueólogos Portugueses declina qualquer responsabilidade por eventuais equívocos ou questões de ordem ética e legal.

Desenho de capa:

Planta do castro de Monte Mozinho (Museu Municipal de Penafiel).

\section{$\hat{\wedge} \mathrm{P}$}

DOS ARQUEÓLOGOS PORTUGUESES

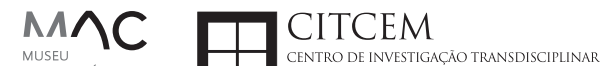
MUSEU
ARQUELLÓGICO
DO CARMO
U.PORTO

FLUP FACULDADE DE LETRAS
UNIVERSIDADE DO PORTO

Apoio

EC para a Ciência 


\section{Índice}

15 Prefácio

José Morais Arnaud

\section{Historiografia e Teoria}

17 Território, comunidade, memória e emoção: a contribuição da história da arqueologia (algumas primeiras e breves reflexões)

Ana Cristina Martins

25 Como descolonizar a arqueologia portuguesa?

Rui Gomes Coelho

41 Arqueologia e Modernidade: uma revisitação pessoal e breve de alguns aspetos da obra homónima de Julian Thomas de 2004

Vítor Oliveira Jorge

57 Dados para a História das Mulheres na Arqueologia portuguesa, dos finais do século XIX aos inícios do século XX: números, nomes e tabelas

Filipa Dimas / Mariana Diniz

73 Retractos da arqueologia portuguesa na imprensa: (in)visibilidades no feminino

Catarina Costeira / Elsa Luís

85 Arqueologia e Arqueólogos no Norte de Portugal Jacinta Bugalhão

101 Vieira Guimarães (1864-1939) e a arqueologia em Tomar: uma abordagem sobre o território e as gentes

João Amendoeira Peixoto / Ana Cristina Martins

115 Os memoráveis? A arqueologia algarvia na imprensa nacional e regional na presente centúria (2001-2019): características, visões do(s) passado(s) e a arqueologia

enquanto marca

Frederico Agosto / João Silva

129 A Evolução da Arqueologia Urbana e a Valorização Patrimonial no Barlavento Algarvio: Os casos de Portimão e Silves

Artur Mateus / Diogo Varandas / Rafael Boavida

\section{Gestão, Valorização e Salvaguarda do Património}

145 O Caderno Reivindicativo e as condições de trabalho em Arqueologia Miguel Rocha / Liliana Matias Carvalho / Regis Barbosa / Mauro Correia / Sara Simões / Jacinta Bugalhão / Sara Brito / Liliana Veríssimo Carvalho / Richard Peace / Pedro Peça / Cézer Santos

155 Os Estudos de Impacte Patrimonial como elemento para uma estratégia sustentável de minimização de impactes no âmbito de reconversões agrícolas Tiago do Pereiro

165 Salvaguarda de Património arqueológico em operações florestais: gestão e sensibilização Filipa Bragança / Gertrudes Zambujo / Sandra Lourenço / Belém Paiva / Carlos Banha / Frederico Tatá Regala / Helena Moura / Jacinta Bugalhão / João Marques / José Correia / Pedro Faria / Samuel Melro

179 Os valores do Património: uma investigação sobre os Sítios Pré-históricos de Arte Rupestre do Vale do Rio Côa e de Siega Verde José Paulo Francisco 
189 Conjugando recursos arqueológicos e naturais para potenciar as visitas ao Geoparque Litoral de Viana do Castelo (Noroeste de Portugal)

Hugo A. Sampaio / Ana M.S. Bettencourt / Susana Marinho / Ricardo Carvalhido

203 Áreas de Potencial Arqueológico na Região do Médio Tejo: Modelo Espacial Preditivo Rita Ferreira Anastácio / Ana Filipa Martins / Luiz Oosterbeek

223 Património Arqueológico e Gestão Territorial: O contributo da Arqueologia para a revisão do PDM de Avis

Ana Cristina Ribeiro

237 A coleção arqueológica do extinto Museu Municipal do Porto - Origens, Percursos e Estudos

Sónia Couto

251 Valpaços - uma nova carta arqueológica

Pedro Pereira / Maria de Fátima Casares Machado

263 Arqueologia na Cidade de Peniche

Adriano Constantino / Luís Rendeiro

273 Arqueologia Urbana: a cidade de Lagos como caso de Estudo Cátia Neto

285 Estratégias de promoção do património cultural subaquático nos Açores. O caso da ilha do Faial

José Luís Neto / José Bettencourt / Luís Borges / Pedro Parreira

297 Carta Arqueológica da Cidade Velha: Uma primeira abordagem

Jaylson Monteiro / Nireide Tavares / Sara da Veiga / Claudino Ramos / Edson Brito /

Carlos Carvalho / Francisco Moreira / Adalberto Tavares

311 Antropologia Virtual: novas metodologias para a análise morfológica e funcional Ricardo Miguel Godinho / Célia Gonçalves

\section{Didáctica da Arqueologia}

327 Como os projetos de Arqueologia podem contribuir para uma comunidade culturalmente mais consciente Alexandra Figueiredo / Claúdio Monteiro / Adolfo Silveira / Ricardo Lopes

337 Educação Patrimonial - Um cidadão esclarecido é um cidadão ativo! Ana Paula Almeida

351 A aproximação da Arqueologia à sala de aula: um caso de estudo no $3^{\circ}$ ciclo do Ensino Básico Luís Serrão Gil

363 Arqueologia 3.o - Pensar e comunicar a Arqueologia para um futuro sustentável Mónica Rolo

377 “Conversa de Arqueólogos" - Divulgar a Arqueologia em tempos de Pandemia Diogo Teixeira Dias

389 Escola Profissional de Arqueologia: desafios e oportunidades Susana Nunes / Dulcineia Pinto / Júlia Silva / Ana Mascarenhas

399 Os Museus de Arqueologia e os Jovens: a oferta educativa para o público adolescente Beatriz Correia Barata / Leonor Medeiros

411 O museu universitário como mediador entre a ciência e a sociedade: o exemplo da secção de arqueologia no Museu de História Natural e da Ciência da Universidade do Porto (MHNC-UP)

Rita Gaspar 
421 Museu de Lanifícios: Real Fábrica de Panos. Atividades no âmbito da Arqueologia Beatriz Correia Barata / Rita Salvado

427 Arqueologia Pública e o caso da localidade da Mata (Torres Novas) Cláudia Manso / Ana Rita Ferreira / Cristiana Ferreira / Vanessa Cardoso Antunes

431 Do sítio arqueológico ao museu: um percurso (também) didático Lídia Fernandes

447 Estão todos convidados para a Festa! E para dançar também... O projecto do Serviço Educativo do Museu Arqueológico do Carmo na $5^{\underline{a}}$ Edição da Festa da Arqueologia Rita Pires dos Santos

459 O “Clã de Carenque”, um projeto didático de arqueologia Eduardo Gonzalez Rocha

469 Mediação cultural: peixe que puxa carroça nas Ruínas Romanas de Troia Inês Vaz Pinto / Ana Patrícia Magalhães / Patrícia Brum / Filipa Santos

481 Didática Arqueológica, experiências do Projeto Mértola Vila Museu Maria de Fátima Palma / Clara Rodrigues / Susana Gómez / Lígia Rafael

\section{Arte Rupestre}

497 Os inventários de arte rupestre em Portugal Mila Simões de Abreu

513 O projeto FIRST-ART - conservação, documentação e gestão das primeiras manifestações de arte rupestre no Sudoeste da Península Ibérica: as grutas do Escoural e Maltravieso Sara Garcês / Hipólito Collado / José Julio García Arranz / Luiz Oosterbeek / António Carlos Silva / Pierluigi Rosina / Hugo Gomes / Anabela Borralheiro Pereira / George Nash / Esmeralda Gomes / Nelson Almeida / Carlos Carpetudo

523 Trabalhos de documentação de arte paleolítica realizados no âmbito do projeto PalæoCôa André Tomás Santos / António Fernando Barbosa / Luís Luís / Marcelo Silvestre / Thierry Aubry

537 Imagens fantasmagóricas, silhuetas elusivas: as figuras humanas na arte do Paleolítico Superior da região do Côa Mário Reis

$55^{1}$ Os motivos zoomórficos representados nas placas de tear de Vila Nova de São Pedro (Azambuja, Portugal) Andrea Martins / César Neves / José M. Arnaud / Mariana Diniz

571 Arte Rupestre do Monte de Góios (Lanhelas, Caminha). Síntese dos resultados dos trabalhos efectuados em 2007-2009 Mário Varela Gomes

599 Gravuras rupestres de barquiformes no Monte de S. Romão, Guimarães, Noroeste de Portugal Daniela Cardoso

613 Círculos segmentados gravados na Bacia do Rio Lima (Noroeste de Portugal): contributos para o seu estudo Diogo Marinho / Ana M.S. Bettencourt / Hugo Aluai Sampaio

631 Equídeos gravados no curso inferior do Rio Mouro, Monção (NW Portugal). Análise preliminar Coutinho, L.M. / Bettencourt, A.M.S / Sampaio, Hugo A.S

645 Paletas na Arte Rupestre do Noroeste de Portugal. Inventário preliminar Bruna Sousa Afonso / Ana M. S. Bettencourt / Hugo A. Sampaio 


\section{Pré-História}

661 O projeto Miño/Minho: balanço de quatro anos de trabalhos arqueológicos Sérgio Monteiro-Rodrigues / João Pedro Cunha-Ribeiro / Eduardo Méndez-Quintas / Carlos Ferreira / Pedro Xavier / José Meireles / Alberto Gomes / Manuel Santonja / Alfredo Pérez-González

677 A ocupação paleolítica da margem esquerda do Baixo Minho: a indústria lítica do sítio de Pedreiras 2 (Monção, Portugal) e a sua integração no contexto regional Carlos Ferreira / João Pedro Cunha-Ribeiro / Sérgio Monteiro-Rodrigues / Eduardo Méndez-Quintas / Pedro Xavier / José Meireles / Alberto Gomes / Manuel Santonja / Alfredo Pérez-González

693 O sítio acheulense do Plistocénico médio da Gruta da Aroeira Joan Daura / Montserrat Sanz / Filipa Rodrigues / Pedro Souto / João Zilhão

703 As sociedades neandertais no Barlavento algarvio: modelos preditivos com recurso aos SIG

Daniela Maio

715 A utilização de quartzo durante o Paleolítico Superior no território dos vales dos rios Vouga e Côa

Cristina Gameiro / Thierry Aubry / Bárbara Costa / Sérgio Gomes / Luís Luís / Carmen Manzano / André Tomás Santos

733 Uma perspetiva diacrónica da ocupação do concheiro do Cabeço da Amoreira (Muge, Portugal) a partir da tecnologia lítica Joana Belmiro / João Cascalheira / Célia Gonçalves

745 Novos dados sobre a Pré-história Antiga no concelho de Palmela. A intervenção arqueológica no sítio do Poceirão I

Michelle Teixeira Santos

757 Problemas em torno de Datas Absolutas Pré-Históricas no Norte do Alentejo Jorge de Oliveira

771 Povoamento pré-histórico nas áreas montanhosas do NO de Portugal: o Abrigo 1 de Vale de Cerdeira Pedro Xavier / José Meireles / Carlos Alves

783 Apreciação do povoamento do Neolítico Inicial na Baixa Bacia do Douro. A Lavra I (Serra da Aboboreira) como caso de estudo Maria de Jesus Sanches

797 O Processo de Neolitização na Plataforma do Mondego: os dados do Sector C do Outeiro dos Castelos de Beijós (Carregal do Sal)

João Carlos de Senna-Martinez / José Manuel Quintã Ventura / Andreia Carvalho / Cíntia Maurício

823 Novos trabalhos na Lapa da Bugalheira (Almonda, Torres Novas) Filipa Rodrigues / Pedro Souto / Artur Ferreira / Alexandre Varanda / Luís Gomes / Helena Gomes / João Zilhão

837 A pedra polida e afeiçoada do sítio do Neolítico médio da Moita do Ourives (Benavente, Portugal)

César Neves

857 Casal do Outeiro (Encarnação, Mafra): novos contributos para o conhecimento do povoamento do Neolítico final na Península de Lisboa.

Cátia Delicado / Carlos Maneira e Costa / Marta Miranda / Ana Catarina Sousa

873 Stresse infantil, morbilidade e mortalidade no sítio arqueológico do Neolítico Final/ Calcolítico ( $4^{\circ}$ e $3^{\circ}$ milénio a.C.) do Monte do Carrascal 2 (Ferreira do Alentejo, Beja) Liliana Matias de Carvalho / Sofia N. Wasterlain 
885 Come together: O Conjunto Megalítico das Motas (Monção, Viana do Castelo) e as expressões Campaniformes do Alto Minho Ana Catarina Basílio / Rui Ramos

899 Trabalhos arqueológicos no sítio Calcolítico da Pedreira do Poio Carla Magalhães / João Muralha / Mário Reis / António Batarda Fernandes

913 O sítio arqueológico de Castanheiro do Vento. Da arquitectura do sítio à arquitectura de um território João Muralha Cardoso

925 Estudo zooarqueológico das faunas do Calcolítico final de Vila Nova de São Pedro (Azambuja, Portugal): Campanhas de 2017 e 2018 Cleia Detry / Ana Catarina Francisco / Mariana Diniz / Andrea Martins / César Neves / José Morais Arnaud

943 As faunas depositadas no Museu Arqueológico do Carmo provenientes de Vila Nova de São Pedro (Azambuja): as campanhas de 1937 a 1967 Ana Catarina Francisco / Cleia Detry / César Neves / Andrea Martins / Mariana Diniz / José Morais Arnaud

959 Análise funcional de material lítico em sílex do castro de Vila Nova de S. Pedro (Azambuja, Portugal): uma primeira abordagem Rafael Lima

971 O recinto da Folha do Ouro 1 (Serpa) no contexto dos recintos de fossos calcolíticos alentejanos

António Carlos Valera / Tiago do Pereiro / Pedro Valério / António M. Monge Soares

\section{Proto-História}

987 Produção de sal marinho na Idade do Bronze do noroeste Português. Alguns dados para uma reflexão

Ana M. S. Bettencourt / Sara Luz / Nuno Oliveira / Pedro P. Simões / Maria Isabel C. Alves / Emílio Abad-Vidal

1001 A estátua-menir do Pedrão ou de São Bartolomeu do Mar (Esposende, noroeste de Portugal) no contexto arqueológico da fachada costeira de entre os rios Neiva e Cávado Ana M. S. Bettencourt / Manuel Santos-Estévez / Pedro Pimenta Simões / Luís Gonçalves

1015 O Castro do Muro (Vandoma/Baltar, Paredes) - notas para uma biografia de ocupação da Idade do Bronze à Idade Média

Maria Antónia D. Silva / Ana M. S. Bettencourt / António Manuel S. P. Silva / Natália Félix

1031 Do Bronze Final à Idade Média - continuidades e hiatos na ocupação de Povoados em Oliveira de Azeméis João Tiago Tavares / Adriaan de Man

1041 As faunas do final da Idade do Bronze no Sul de Portugal: leituras desde o Outeiro do Circo (Beja)

Nelson J. Almeida / Íris Dias / Cleia Detry / Eduardo Porfírio / Miguel Serra

1055 A Espada do Monte das Oliveiras (Serpa) - uma arma do Bronze Pleno do Sudoeste Rui M. G. Monge Soares / Pedro Valério / Mariana Nabais / António M. Monge Soares

1065 São Julião da Branca (Albergaria-a-Velha) - Investigação e valorização de um povoado do Bronze Final

António Manuel S. P. Silva / Paulo A. P. Lemos / Sara Almeida e Silva / Edite Martins de Sá

1083 Do castro de S. João ao Mosteiro de Santa Clara: notícia de uma intervenção arqueológica, em Vila do Conde Rui Pinheiro 
1095 O castro de Ovil (Espinho), um quarto de século de investigação - resultados e questões em aberto

Jorge Fernando Salvador / António Manuel S. P. Silva

1111 O Castro de Salreu (Estarreja), um povoado proto-histórico no litoral do Entre Douro e Vouga

Sara Almeida e Silva / António Manuel S. P. Silva / Paulo A. P. Lemos / Edite Martins de Sá

1127 Castro de Nossa Senhora das Necessidades (Sernancelhe): uma primeira análise artefactual Telma Susana O. Ribeiro

${ }_{1141}$ A cividade de Bagunte. O estado atual da investigação Pedro Brochado de Almeida

1153 Zoomorfos na cerâmica da Idade do Ferro no NW Peninsular: inventário, cronologias e significado Nuno Oliveira / Cristina Seoane

1163 Vasos gregos em Portugal: diferentes maneiras de contar a história do intercâmbio cultural na Idade do Ferro

Daniela Ferreira

1175 Os exotica da necrópole da Idade do Ferro do Olival do Senhor dos Mártires (Alcácer do Sal) no seu contexto regional

Francisco B. Gomes

\section{Antiguidade Clássica e Tardia}

1191 O uso de madeira como combustível no sítio da Quinta de Crestelos (Baixo Sabor): da Idade do Ferro à Romanização Filipe Vaz / João Tereso / Sérgio Simões Pereira / José Sastre / Javier Larrazabal Galarza / Susana Cosme / José António Pereira / Israel Espi

1207 Cultivos de Época Romana no Baixo Sabor: continuidade em tempos de mudança? João Pedro Tereso / Sérgio Simões Pereira / Filipe Santos / Luís Seabra / Filipe Vaz

1221 A casa romana na Hispânia: aplicação dos modelos itálicos nas províncias ibéricas Fernanda Magalhães / Diego Machado / Manuela Martins

1235 As pinturas murais romanas da Rua General Sousa Machado, n. ${ }^{5}$ 1, Chaves José Carvalho

1243 Trás do Castelo (Vale de Mir, Pegarinhos, Alijó) - Uma exploração agrícola romana do Douro

Tony Silvino / Pedro Pereira

1255 A sequência de ocupação no quadrante sudeste de Bracara Augusta: as transformações de uma unidade doméstica Lara Fernandes / Manuela Martins

1263 Os Mosaicos com decoração geométrica e geométrico-vegetalista dos sítios arqueológicos da área do Conuentus Bracaraugustanus. Novas abordagens quanto à conservação, restauro, decoração e datação Maria de Fátima Abraços / Licínia Wrench

1277 “Casa Romana” do Castro de São Domingos (Cristelos, Lousada): Escavação, Estudo e Musealização Paulo André de P. Lemos

1291 A arqueobotânica no Castro de Guifões (Matosinhos, Noroeste de Portugal): O primeiro estudo carpológico

Luís Seabra / Andreia Arezes / Catarina Magalhães / José Varela / João Pedro Tereso 
1305 Um Horreum Augustano na Foz do Douro (Monte do Castelo de Gaia, Vila Nova de Gaia) Rui Ramos

1311 Ponderais romanos na Lusitânia: padrões, formas, materiais e contextos de utilização Diego Barrios Rodríguez

1323 Um almofariz centro-itálico na foz do Mondego

Marco Penajoia

1335 Estruturas romanas de Carnide - Lisboa Luísa Batalha / Mário Monteiro / Guilherme Cardoso

1347 O contexto funerário do sector da "necrópole NO" da Rua das Portas de S. Antão (Lisboa): o espaço, os artefactos, os indivíduos e a sua interconectividade na interpretação do passado Sílvia Loja, José Carlos Quaresma, Nelson Cabaço, Marina Lourenço, Sílvia Casimiro, Rodrigo Banha da Silva, Francisca Alves-Cardoso

${ }_{1361}$ Povoamento em época Romana na Amadora - resultados de um projeto pluridisciplinar Gisela Encarnação / Vanessa Dias

1371 A Arquitectura Residencial em Mirobriga (Santiago do Cacém): contributo a partir de um estudo de caso Filipe Sousa / Catarina Felício

${ }_{1385}$ O fim do ciclo. Saneamento e gestão de resíduos nos edifícios termais de Mirobriga (Santiago do Cacém)

Catarina Felício / Filipe Sousa

1399 Balsa, Topografia e Urbanismo de uma Cidade Portuária Vítor Silva Dias / João Pedro Bernardes / Celso Candeias / Cristina Tété Garcia

1413 No Largo das Mouras Velhas em Faro (2017): novas evidências da necrópole norte de Ossonoba e da sua ocupação medieval Ricardo Costeira da Silva / Paulo Botelho / Fernando Santos / Liliana Nunes

1429 Instrumentos de pesca recuperados numa fábrica de salga em Ossonoba (Faro) Inês Rasteiro / Ricardo Costeira da Silva / Paulo Botelho

1439 A Necrópole Romana do Eirô, Duas Igrejas (Penafiel): intervenção arqueológica de 2016 Laura Sousa / Teresa Soeiro

1457 Ritual, descarte ou afetividade? A presença de Canis lupus familiaris na Necrópole Noroeste de Olisipo (Lisboa)

Beatriz Calapez Santos / Sofia Simões Pereira / Rodrigo Banha da Silva / Sílvia Casimiro / Cleia Detry / Francisca Alves Cardoso

1467 Dinâmicas económicas em Bracara na Antiguidade Tardia Diego Machado / Manuela Martins / Fernanda Magalhães / Natália Botica

1479 Cerâmicas e Vidros da Antiguidade Tardia do Edifício sob a Igreja do Bom Jesus (Vila Nova de Gaia) Joaquim Filipe Ramos

1493 Novos contributos para a topografia histórica de Mértola no período romano e na Antiguidade Tardia Virgílio Lopes

\section{8. Época Medieval}

1511 Cerâmicas islâmicas no Garb setentrional "português": algumas evidências e incógnitas Constança dos Santos / Helena Catarino / Susana Gómez / Maria José Gonçalves / Isabel Inácio / Gonçalo Lopes / Jacinta Bugalhão / Sandra Cavaco / Jaquelina Covaneiro / Isabel Cristina Fernandes / Ana Sofia Gomes 
1525 Contributo para o conhecimento da cosmética islâmica, em Silves, durante a Idade Média Rosa Varela Gomes

1537 Yábura e o seu território - uma análise histórico-arqueológica de Évora entre os séculos VIII-XII José Rui Santos

1547 A encosta sul do Castelo de Palmela - resultados preliminares da escavação arqueológica Luís Filipe Pereira / Michelle Teixeira Santos

1559 A igreja de São Lourenço (Mouraria, Lisboa): um conjunto de silos e de cerâmica medieval islâmica

Andreia Filipa Moreira Rodrigues

1571 O registo material de movimentações populacionais no Médio Tejo, durante os séculos XII-XIII. Dois casos de "sunken featured buildings", nos concelhos de Cartaxo e Torres Novas Marco Liberato / Helena Santos / Nuno Santos

1585 O nordeste transmontano nos alvores da Idade média. Notas para reflexão Ana Maria da Costa Oliveira

1601 Sepulturas escavadas na rocha do Norte de Portugal e do Vale do Douro: primeiros resultados do Projecto SER-NPVD

Mário Jorge Barroca / César Guedes / Andreia Arezes / Ana Maria Oliveira

1619 "Portucalem Castrum Novum" entre o Mediterrâneo e o Atlântico: o estudo dos materiais cerâmicos alto-medievais do arqueossítio da rua de D. Hugo, nํ. 5 (Porto) João Luís Veloso

1627 A Alta Idade Média na fronteira de Lafões: notas preliminares sobre a Arqueologia no Concelho de Vouzela

Manuel Luís Real / Catarina Tente

1641 Um conjunto cerâmico medieval fora de portas: um breve testemunho aveirense Susana Temudo

${ }_{1651}$ Os Lóios do Porto: uma perspetiva integrada no panorama funerário da Baixa Idade Média à Época Moderna em meios urbanos em Portugal

Ana Lema Seabra

1659 O Caminho Português Interior de Santiago como eixo viário na Idade Média Pedro Azevedo

1665 Morfologia Urbana: Um exercício em torno do Castelo de Ourém André Donas-Botto / Jaqueline Pereira

1677 Intervenção arqueológica na Rua Marquês de Pombal/Largo do Espírito Santo (Bucelas, Loures)

Florbela Estêvão / Nathalie Antunes-Ferreira / Dário Ramos Neves / Inês Lisboa

1691 O Cemitério Medieval do Poço do Borratém e a espacialidade funerária na cidade de Lisboa Inês Belém / Vanessa Filipe / Vasco Noronha Vieira / Sónia Ferro / Rodrigo Banha da Silva

1705 Um Espaço Funerário Conventual do séc. XV em Lisboa: o caso do Convento de São Domingos da Cidade Sérgio Pedroso / Sílvia Casimiro / Rodrigo Banha da Silva / Francisca Alves Cardoso

\section{9. Época Moderna e Contemporânea}

1721 Arqueologia Moderna em Portugal: algumas reflexões críticas em torno da quantificação de conjuntos cerâmicos e suas inferências históricas e antropológicas Rodrigo Banha da Silva / André Bargão / Sara da Cruz Ferreira

1733 Faianças de dois contextos entre os finais do século XVI e XVIII do Palácio dos Condes de Penafiel, Lisboa

Martim Lopes / Tomás Mesquita 
1747 Um perfil de consumo do século XVIII na foz do Tejo: O caso do Mercado da Ribeira, Lisboa Sara da Cruz Ferreira / Rodrigo Banha da Silva / André Bargão

1761 Os Cachimbos dos Séculos XVII e XVIII do Palácio Mesquitela e Convento dos Inglesinhos (Lisboa)

Inês Simão / Marina Pinto / João Pimenta / Sara da Cruz Ferreira / André Bargão / Rodrigo Banha da Silva

1775 "Tomar os fumos da erua que chamão em Portugal erua sancta». Estudo de Cachimbos provenientes da Rua do Terreiro do Trigo, Lisboa

Miguel Martins de Sousa / José Pedro Henriques / Vanessa Galiza Filipe

1787 Cachimbos de Barro Caulínitico da Sé da Cidade Velha (República de Cabo Verde)

Rodrigo Banha da Silva / João Pimenta / Clementino Amaro

1801 Algumas considerações sobre espólio não cerâmico recuperado no Largo de Jesus (Lisboa) Carlos Boavida

1815 Adereços de vidro, dos séculos XVI-XVIII, procedentes do antigo Convento de Santana de Lisboa (anéis, braceletes e contas)

Joana Gonçalves / Rosa Varela Gomes / Mário Varela Gomes

1837 Da ostentação, luxo e poder à simplicidade do uso quotidiano: arqueologia e simbologia de joias e adornos da Idade Moderna Portuguesa Jéssica Iglésias

1849 Os amuletos em Portugal - dos objetos às superstições: o coral vermelho Alexandra Vieira

1865 Cerâmicas de Vila Franca de Xira nos séculos XV e XVI Eva Pires

1879 «Não passa por teu o que me pertence». Marcas de individualização associadas a faianças do Convento de Nossa Senhora de Aracoeli, Alcácer do Sal Catarina Parreira / Íris Fragoso / Miguel Martins de Sousa

1891 Cerâmica de Leiria: alguns focos de produção

Jaqueline Pereira / André Donas-Botto

1901 Os Fornos na Rua da Biquinha, em Óbidos Hugo Silva / Filipe Oliveira

1909 A casa de Pêro Fernandes, contador dos contos de D. Manuel I: o sítio arqueológico da Silha do Alferes, Seixal (século XVI) Mariana Nunes Ferreira

1921 O Alto da Vigia (Sintra) e a vigilância e defesa da costa Alexandre Gonçalves / Sandra Santos

1937 O contexto da torre sineira da Igreja de Santa Maria de Loures Paulo Calaveira / Martim Lopes

1949 A Necrópole do Hospital Militar do Castelo de São Jorge e as práticas funerárias na Lisboa de Época Moderna Susana Henriques / Liliana Matias de Carvalho / Ana Amarante / Sofia N. Wasterlain

1963 SAND - Sarilhos Grandes Entre dois Mundos: o adro da Igreja e a Paleobiologia dos ossos humanos recuperados

Paula Alves Pereira / Roger Lee Jesus / Bruno M. Magalhães

1975 Expansão urbana da vila de Cascais no século XVII e XVIII: a intervenção arqueológica na Rua da Vitória no 15 a 17

Tiago Pereira / Vanessa Filipe

1987 Novos dados para o conhecimento do Urbanismo de Faro em época Moderna Ana Rosa 
1995 Um exemplo de Arqueologia Urbana em Alcoutim: o Antigo Edifício dos CTT Marco Fernandes / Marta Dias / Alexandra Gradim / Virgílio Lopes / Susana Gómez Martínez

2007 Palácio dos Ferrazes (Rua das Flores/Rua da Vitória, Porto): a cocheira de Domingos Oliveira Maia

Francisco Raimundo

2021 As muitas vidas de um edifício urbano: História, Arqueologia e Antropologia no antigo Recreatório Paroquial de Penafiel Helena Bernardo / Jorge Sampaio / Marta Borges

2035 O convento de Nossa Senhora da Esperança de Ponta Delgada: o contributo da arqueologia para o conhecimento de um monumento identitário João Gonçalves Araújo / N’Zinga Oliveira

2047 Arqueologia na ilha do Corvo... em busca da capela de Nossa Senhora do Rosário Tânia Manuel Casimiro / José Luís Neto / Luís Borges / Pedro Parreira

2059 Perdidos à vista da Costa. Trabalhos arqueológicos subaquáticos na Barra do Tejo Jorge Freire / José Bettencourt / Augusto Salgado

2071 Arqueologia marítima em Cabo Verde: enquadramento e primeiros resultados do projecto CONCHA

José Bettencourt / Adilson Dias / Carlos Lima / Christelle Chouzenoux / Cristóvão Fonseca / Dúnia Pereira / Gonçalo Lopes / Inês Coelho / Jaylson Monteiro / José Lima / Maria Eugénia Alves / Patrícia Carvalho / Tiago Silva

2085 Trabalhos arqueológicos na Cidade Velha (Ribeira Grande de Santiago, Cabo Verde): reflexões sobre um projecto de investigação e divulgação patrimonial André Teixeira / Jaylson Monteiro / Mariana Mateus / Nireide Tavares / Cristovão Fonseca / Gonçalo C. Lopes / Joana Bento Torres / Dúnia Pereira / André Bargão / Aurélie Mayer / Bruno Zélie / Carlos Lima / Christelle Chouzenoux / Inês Henriques / Inês Pinto Coelho / José Lima / Patrícia Carvalho / Tiago Silva

2103 A antiga fortificação de Quelba / Khor Kalba (E.A.U.). Resultados de quatro campanhas de escavações, problemáticas e perspectivas futuras Rui Carita / Rosa Varela Gomes / Mário Varela Gomes / Kamyar Kamyad

2123 Colónias para homens novos: arqueologia da colonização agrária fascista no noroeste ibérico Xurxo Ayán Vila / José Mạ . Señorán Martín 


\title{
CONJUGANDO RECURSOS ARQUEOLÓGICOS E NATURAIS PARA POTENCIAR AS VISITAS AO GEOPARQUE LITORAL DE VIANA DO CASTELO (NOROESTE DE PORTUGAL)
}

\author{
Hugo A. Sampaio ${ }^{1,2}$, Ana M.S. Bettencourt ${ }^{1}$, Susana Marinho ${ }^{3}$, Ricardo Carvalhido 4
}

\begin{abstract}
RESUMO
O Geoparque Litoral de Viana do Castelo ocupa $320 \mathrm{~km}^{2}$ do NW português. Inclui áreas costeiras e montanhosas e contextos socioculturais e territoriais distintos e um conjunto único e diverso de sítios arqueológicos. O presente trabalho pretende mostrar como alguns desses sítios detêm potencial lúdico e educativo, por si só ou quando articulados com os restantes recursos geológicos.

Sublinham-se e propõem-se certas ações para a valorização do património arqueológico localizado no interior e limites do Geoparque, evidenciando o que já foi feito para conhecer e proteger este importante (mas frágil) conjunto de vestígios do passado.

Palavras-chave: Património cultural, Património natural, Valorização de sítios arqueológicos, Turismo
\end{abstract} arqueológico em rede.

\begin{abstract}
The Coastal Geopark of Viana do Castelo occupies $320 \mathrm{~km} 2$ of the Portuguese NW. It includes coastal and mountainous areas and distinct sociocultural and territorial contexts, and a unique and diverse set of archaeological sites. The present work intends to show how some of these sites have leisure and educational potential on their own, or when articulated with other geological resources. Some actions are highlighted and proposed for the valorisation of the archaeological heritage located inside the limits of the Geopark, evidencing what has already been done to know and protect this important (but fragile) set of past traces. Keywords: Cultural heritage, Natural heritage, Valorisation of archaeological sites, Archaeological networking tourism.
\end{abstract}

\section{INTRODUÇÃO}

O património é o legado do passado que corresponde a tudo o que é criado pela Natureza ou que resulta da agência humana e que se multiplica em diversas manifestações, como o património natural e cultural (Barranha, 2016, pp. 27-30). Numa perspetiva racional, este último resulta de um processo cultural (Waterton \& Smith, 2009, pp. 1012) que espelha o uso presente do passado e a forma como as sociedades o valorizam, seja ele tangível ou intangível (Timothy \& Tahan, 2020, p. 5). A sua heterogeneidade inclui o património arqueológico, caraterizado como parcial, frágil e não renová-

\footnotetext{
1. Laboratório de Paisagens Património e Território (Lab2PT) | Departamento de História do Instituto de Ciências Sociais da Universidade do Minho; hugoaluai@gmail.com; bettencourt.ana@gmail.com.

2. Centro de Investigação em Turismo, Inovação e Desenvolvimento (CITur) | Escola Superior de Hotelaria e Turismo do Instituto Politécnico do Cávado e do Ave.

3. Escola Superior de Hotelaria e Turismo do Instituto Politécnico do Cávado e do Ave; susmarinho@gmail.com.

4. Câmara Municipal de Viana do Castelo | Diretor do Geoparque Litoral de Viana do Castelo; carvalhido@cm-viana-castelo.pt
} 
vel (ICOMOS, 1990, p. 20), caracterizado pela sua fragmentação e pouca visibilidade (Solsona Monzonis \& Rico Cánovas, 2014, p. 38). Esta condição levanta sérios desafios à sua valorização, cabendo à Arqueologia a construção de significados e de discursos interpretativos perceptíveis pelo público em geral (Hodder \& Hutson, 2003, p. 221). Além da sua natureza complexa, deve referir-se a falta de investimento (humano e financeiro) e de interesse político na sua recuperação. Como tal, a sua especificidade faz com que, muitas vezes, seja desconsiderado enquanto recurso turístico (Yamamoto \& Nieto Hernández, 2013, p. 78). Algumas estratégias, contudo, têm tentado contrariar esta situação, como os Projetos ArcheoMed 5 , ARCHEOMEDSITES $^{6}$ ou NÒSTOI 7 , por exemplo, ou as linhas de orientação propostas pela própria UNESCO (2001), quando defende que "heritage in all its forms must be preserved, enhanced and handed on to future generations as a record of human experience and aspirations". O próprio World Heritage Committee e o Programa World Heritage and Sustainable Tourism $^{8}$ visam promover a maximização do usufruto turístico do Património Mundial, nunca descurando da sua salvaguarda (WHC, 2020). É em relação a este aspecto que começa o verdadeiro desafio: como podem os arqueólogos, técnicos de património e stakeholders utilizar este registo parcial e altamente secionado do passado como atrativo turístico? Como pode a sua interpretação tornar-se perceptível e ser transmitida como mensagem, ao público em geral?

Em muitos casos, os turistas sentem-se impelidos a visitar vestígios arqueológicos pelo interesse no passado, pela originalidade, pela observação na primeira pessoa e pela curiosidade e busca de uma experiência diferente (Walker, 2005, p. 6o-61).

Se é certo que o perfil do turista arqueológico possa corresponder ao visitante de média idade ou mais velho, bem educado, com formação académica, que permanece mais tempo nos destinos que visita e que gasta mais dinheiro (Timothy, 2011, pp. 27-30), não é menos verdade que há franjas de turistas mais

\footnotetext{
5. http://www.archeomedproject.eu/archeomed-project.

6. https://www.archeomedsites.beniculturali.it/project/ presentation/.

7. https://www.nostoi.xyz.

8. https://whc.unesco.org/en/tourism/.
}

novos igualmente interessados, ainda que com menos poder de compra, pelo que explorar novas formas de valorizar o património cultural é uma ação fulcral para conseguir uma atividade turística mais sustentável e que vai de encontro aos princípios definidos pela World Tourism Organization ${ }^{9}$ (UNWTO, 2020). Assim, e de acordo com os diferentes tipos de património, devem implementar-se diferentes estratégias. Estas deverão considerar os recursos disponíveis de uma determinada região, cidade ou país sem, contudo, menosprezar princípios básicos de sustentabilidade ambiental, social e económica (UNESCO, 2006).

Por seu turno, o Turismo Cultural, onde se insere o arqueológico, enquanto atividade económica tem, também, a capacidade de ligar as populações locais ao seu património (Thomas, 2017, p. 14) e de fomentar a identidade cultural (Mateus, 2003, p. 21), em especial nos contextos em que estão envolvidas minorias ou comunidades de menor expressão. Tal advém da capacidade que o património cultural tem de servir de ponte com a ancestralidade, com $\mathrm{o}(\mathrm{s})$ sentido(s) de lugar e as origens identitárias (Davidson \& Brandon, 2012, pp. 606-607). Sendo verdade que nem todo o património arqueológico é passível de ser valorizado turisticamente, a UNESCO (2006) destaca a viabilidade do uso do património para fins turísticos embora tendo em conta o necessário e equilibrado "casamento" entre sustentabilidade, cultura e turismo. Mas tornar o património arqueológico visitável é, também, abrir portas a fenómenos menos positivos, tais como: o vandalismo dos sítios; a produção de lixo ou o desgaste resultante do excesso de visitantes (Timothy, 2011, pp. 158-163). Vários países que apostaram intensamente no turismo arqueológico, como o Peru (Machu Picchu), a Jordânia (Petra), o Reino Unido (Stonehenge) ou o Egito (pirâmides de Gizé), por exemplo, vêm-se constantemente desafiados pela tarefa de combater os excessos "consumistas" dos produtos arqueológicos (Timothy \& Tahan, 2020, p. 16). Com o objetivo de controlar estas desvantagens, Enseñat-Soberanis et alii (2019, pp. 347-351) destacam três estratégias possíveis nos casos sensíveis: (a) estratégias restritivas, através do controlo do número de visitantes, proibindo acessos a determinados espaços ou lugares, a fotografias ou à manipulação de património; (b) estratégias redistri-

9. https://www.unwto.org/sustainable-development. 
butivas, baseadas na criação de números restritos de visitantes para determinadas áreas e com horas de visita marcada, o que pode acontecer de forma recorrente ou ser aplicado em horas de ponta; (c) estratégias interpretativas, com especial ênfase na demonstração e no ensino do valor que o património tem, persuadindo os visitantes a alterar os seus comportamentos negativos para com o mesmo. Se proibir não se mostra justo e reencaminhar para outras atrações nem sempre é exequível, crê-se que a estratégia pela via da educação poderá ser, definitivamente, uma opção, em especial apostando na formação da população mais nova, dos gestores, dos decisores, dos profissionais de Turismo e dos visitantes do futuro.

Na maioria do Noroeste de Portugal, o conjunto de sítios arqueológicos, sendo de grande interesse científico, tem especificidades que implicam que a sua valorização patrimonial e turística se faça em articulação com outros recursos e com estratégias interpretativas. Estas especificidades relacionam-se com o seu estado de conservação, a falta de conhecimento da sua importância por parte da população local e dos decisores políticos e, também, as suas características intrínsecas, por vezes pouco espetaculares para poderem servir de produto âncora por si só. Tal é o caso do património arqueológico que se encontra no Geoparque Litoral de Viana do Castelo (GLVC). Deste modo, o objectivo deste trabalho é procurar estratégias para interligar o património arqueológico com outros recursos naturais e culturais existentes neste território.

\section{O GEOPARQUE LITORAL DE VIANA DO CASTELO}

Um Geoparque é uma área com um território bem definido que integra em si um património geológico de relevância, a diferentes escalas. No conjunto, reúne um conjunto significativo de geossítios cuja importância para a compreensão e conhecimento da história geológica pode ser local, regional, nacional ou internacional. À luz dos pressupostos Gobal Geopark Network"10 "Geoparks are single, unified geographical areas where sites and landscapes of international geological significance are managed with a holistic concept of protection, education and sustainable development (...) [which] uses its geo-

10. http://www.globalgeopark.org/aboutGGN/6398.htm. logical heritage, in connection with all other aspects of the area's natural and cultural heritage, to enhance awareness and understanding of key issues (...) [giving] local people a sense of pride in their region and strengthen their identification with the area" (GGN, 2020). Como tal, estão associados a uma estratégia de desenvolvimento sustentável que inclui a integração de aspetos culturais e naturais de diferentes âmbitos, como o património cultural (incluindo o arqueológico, histórico, gastronómico, artesanal ou imaterial) e os recursos ecológicos.

O Geoparque Litoral de Viana do Castelo (GLVC), aspirante à Global Geopark Network, alberga fisicamente todo o concelho de Viana do Castelo (Noroeste de Portugal). Totalizando uma área de $320 \mathrm{~km}^{2}$, as suas características geomorfológicas permitem aceder a diferentes geossítios. Assim, do contacto entre o oceano Atlântico, o estuário do rio Lima e a Serra de Arga, decorre uma riqueza ecológica e cultural de inegável valor turístico (Carvalhido, Ribeiro \& Cunha, 2017, p. 27) (Figura 1).

No total, o GLVC integra um conjunto de monumentos naturais classificados e de valências naturais e culturais de valor histórico-cultural. Estes mostram-se propícios à prática de caminhadas, ciclismo e hipismo, interligando diversos sítios de interesse científico e cultural entre si (Carvalhido, 2016, p. 2). Entre estas valências figura um grupo diversificado de vestígios arqueológicos pertencentes a diferentes períodos cronológico-culturais, desde a Pré-história à contemporaneidade que, associados ao conhecimento histórico, são determinantes para a compreensão do passado e da história local e para desenhar o quadro socioeconómico da região, ao longo do tempo.

\subsection{Recursos naturais e recursos arqueológicos}

No total, O GLVC integra 13 geossítios classificados de importância local, regional, nacional e internacional (Carvalhido, Ribeiro \& Cunha, 2017, p. 27). Entre estes, especial destaque para aqueles cuja articulação com vestígios arqueológicos é passível de ajudar na sua valorização.

O geossítio de Canto Marinho, na freguesia de Carreço, inclui cerca de 713 pias salineiras escavadas em rochas de micaxisto do período Ordovícico (Costa et alii, 2012, p.104) dispersas por 24 hectares (Figura 2). Situação idêntica em termos arqueológicos, ocorre no geossítio da Ribeira de Anha, em Darque (Carvalhido, 2016, p. 31, Bettencourt et alii, 2020, 
no prelo). O Alcantilado de Montedor, a norte de Canto Marinho e também em Carreço, importa pela geomorfologia, tectónica e alterações da plataforma costeira (Carvalhido, Ribeiro \& Cunha, 2017, p. 27) e integra as gravuras rupestres de Fornelos, cujo valor e particularidade de narrativa interpretativa-se mostra de inegável valor (Bettencourt et alii, 2017). O geossítio das Ínsuas do Lima valoriza o "importante couto salineiro de Portuzelo-Meadela" (Carvalhido, 2016, p. 27) e o das Cristas Quartzíticas do Campo Mineiro de Folgadoiro-Verdes tem uma ampla relação com a mineração (Alves, 2014, p. 1415; Carvalhido, Pereira, Cunha, 2017, p. 28).

Em termos de infraestruturas de apoio, o GLVC conta com um passadiço em madeira ao longo da costa atlântica que permite a visita de diferentes geossítios. A sua existência é crucial, pois favorece a visitação daqueles sítios e permite sensibilizar, envolver e aproximar as populações locais, e o público em geral, do património existente e promover o conhecimento geológico e cultural. Vinca-se, assim, a estreita relação entre o GLVC e estratégias sustentáveis onde a congregação dos seus recursos ecológicos e histórico-culturais se torna uma excelente ferramenta para o desenvolvimento da economia regional, enfatizando a prática do Geoturismo, do Turismo Natureza, do Turismo Cultural ou Histórico, não esquecendo a promoção da Gastronomia, dos Vinhos, do Artesanato e de muitas outras tradições e costumes locais.

A área do GLVC compreende um total de 156 sítios arqueológicos cartografados ${ }^{11}$, dos quais 43 se inserem na Pré-história, 39 na Idade do Ferro, 31 na época romana e 46 na Idade Média (CMVC, 2020). Apesar do trabalho já realizado, o número de sítios arqueológicos conhecidos, desde 2014, é manifestamente maior e mais diversificado em termos cronológicos, podendo ser contabilizado na ordem dos milhares (Bettencourt \& Abad-Vidal, 2014; Santos, 2013, 2014; Bettencourt \& Santos-Estévez, 2018; Bettencourt, 2019; Costa et alii, 2019; Oliveira, 2019; Oliveira \& Bettencourt, 2020; Bettencourt et alii, 2020, no prelo), o que potencia a sua importância científica e estratégica em termos turísticos. Tendo presente a estreita relação com a Geologia, este texto centra-se em três recursos arqueológicos passíveis de conjugação,

11. http://www.cm-viana-castelo.pt/pt/roteiro-arqueologico. nomeadamente: os associados à produção de sal; os associados à extração mineira de estanho, ouro e volfrâmio; e os relacionados com a arte rupestre, aos quais se dará maior destaque.

\subsubsection{Os recursos associados à produção de sal}

Além das já mencionadas pias salineiras de Canto Marinho (Costa et alii, 2012, 2019, p. 104) (Figura 2), destacam-se os inúmeros núcleos deste tipo de ocorrências desde, pelo menos, a foz da Ribeira de Anha, em Darque, até Afife, com especial destaque para os núcleos existentes entre Fornelos e o Forte de Paçô e os das mais diversas praias da freguesia de Afife (Bettencourt et alii, 202O; Bettencourt et alii, no prelo). Se bem que tradicionalmente classificadas como da Idade do Ferro (Almeida, 2005, p. 148; Costa et alii, 2012, p. 96, 2019), novos dados possibilitaram recuar esta atividade, no litoral de Viana do Castelo, para a Idade do Bronze, cerca de 1000 anos antes do que se pensava (Bettencourt et alii, 2020; Bettencourt et alii, no prelo; Oliveira \& Bettencourt, 2020).

Se as pias salineiras cortadas na rocha puderam ser reutilizadas na Idade do ferro e durante a época romana e medieval, a metodologia de extração de sal complexificou-se. Vestígios desta atividade, datáveis destes períodos, existem também no litoral do Geoparque, entre as freguesias de Areosa e Afife ${ }^{12}$, embora ainda não devidamente estudados. A produção de sal permaneceu no estuário do Lima até aos séculos XVIII e XIX (Fernandes, 1994) existindo, ainda, vestígios dessa atividade nas freguesias da Meadela, Santa Marta de Portuzelo e Darque, perfeitamente enquadráveis no âmbito do geossítio das Ínsuas do Lima (Carvalhido, 2016, p. 27).

Contribuindo para a sua preservação e em associação a esta atividade deveria ser valorizado o importante antigo complexo de seca do Bacalhau, no Cais Novo, junto à atual rua da Seca, na freguesia de Darque (Figura 3). O seu estado de ruina, se valorizado e musealizado, poderia articular-se com o antigo Navio-Hospital que acompanhava a frota da pesca do bacalhau à Terra Nova (Fundação Gil Eannes, 2007) - o atual Navio-Museu Gil Eanes, atracado junto à Doca Comercial de Viana do Castelo, produto turístico já existente no seio do Geoparque. A importância desta atividade ancestral na

12. Conforme comunicação pessoal do Engenheiro Horácio Faria, da Câmara Municipal de Viana do Castelo. 
região poderia ainda relacionar-se, em formato de Centro Interpretativo, com as oscilações da linha da costa e a atual transgressão marinha.

\subsubsection{Os recursos associados à extração mineira de estanho, ouro e volfrâmio}

Segundo a Carta Geológica de Portugal, folha 5-A, à escala 1:50 ooo (Teixeira, Medeiros \& Coelho, 1972, p. 34-35), a área do Geoparque é rica em cassiterite, ouro e volfrâmio. A cassiterite era abundante, em especial nas freguesias de Cardielos, Nogueira e Vilar de Murtede, bem como nas aluviões do estuário do Lima (Alves, 1996). Estas caraterísticas tornaram esta área predileta para as primeiras populações mineiras, em especial os metalurgistas da Pré-história, cuja necessidade de estanho levou à procura e coleta daquele recurso ainda durante $\mathrm{o} 2^{\circ}$ milénio a.C., isto é, na Idade do Bronze Médio, comprovadas pelas descobertas do machado de bronze de Bandeira, na freguesia de Santa maria Maior (Fernandes et alli, 2011) e do Folgadoiro, na freguesia de Santa Maria Maior (Fernandes et alli, 2011) e no Folgadoiro, na freguesia de Vilar de Murteda, este último em contexto de limpeza de escombreiras de mineração (Zbyszewski \& Ferreira, 1955, p. 50, fig. 2). Do Bronze Final há a registar os depósitos de Cobidalto, na freguesia da Areosa (Bettencourt et alli, 2014) e o de Pereiras Pequenas, na freguesia de Vila de Punhe (Manteiga Brea, Bettencourt, Comendador Rey, 2014), um dos maiores do Noroeste de Portugal. A mineração durante o Bronze Final e a Idade do Ferro atesta-se, por exemplo, nos Castros de Santo António, em Afife (Oliveira \& Bettencourt, 2020) e no Castro de Terronha, em Cardielos (Oliveira, 2019), respetivamente, e a romana na freguesia de Vila Mou (Moreira, 1981, pp. 405-407; Brochado, 2004, p. 38) e no Alto da Bouça da Breia, Folgadoura (Alves, 2014, p. 607). A última grande etapa da mineração foi a do estanho e do volfrâmio, em especial no período entre as duas Grandes Guerras (Nunes, 2010, pp. 10o, 112, 375, 397-398). A serra d'Arga, onde a concentração das explorações é maior, totaliza 21 concessões mineiras de estanho ocorridas em especial a partir das décadas de 30 e 40 do século XX (Lima, 2006, p. 257). No século XX é de destacar o complexo mineiro do Folgadoiro, com inúmeras cortas e minas em poço/galeria, bem como as importantes cortas de extração de volfrâmio, ainda visíveis a céu aberto, nas áreas de Montaria, Vilar de Murteda, Amonde ou Lanheses (Lima, 2006, pp. $84-85,103,203,206,243,245,250,253,255$, $257,259,280,288,466,558,604)$.

A valorização destes recursos com a criação de itinerários mineiros seria uma forma de associar, com sucesso e grande interesse científico e didático, um bom número de recursos geológicos e arqueológicos, desde a Pré-história à Arqueologia Industrial.

\subsubsection{A arte rupestre}

A arte rupestre, pela superfície em que é gravada, está intrinsecamente relacionada com a forma e as características litológicas do afloramento (Bettencourt et alii, 2017, p. 168). O estudo, ainda que preliminar, da arte rupestre das serras de Santa Luzia (Cardoso, 1897; Viana, 1960; Lanhas, 1969; Baptista \& Magalhães, 1985; Baptista, 1986; Alves, 1989; Santos, 2013, 2014; Bettencourt et alii, 2017; Santos-Estévez \& Bettencourt, 2017; Santos-Estévez et alii, 2017; Moreira, 2018; Bettencourt, 2019) e de Perre (Paço, 1942; Loureiro, 2006; Silva, 2008; 2014a, 2014b; Bettencourt, 2013, Bettencourt \& Santos-Estévez, 2018), assim como do Monte do Santinho/Monte de Roques (Magalhães, 2016, pp. 41-43) tem revelado o grande número, diversidade e importância deste recurso arqueológico no território do GLVC. No Corpus Virtual de Arte Rupestre do Noroeste-CVARN (www.cvarn. org), portal de difusão da arte rupestre do Noroeste disponibilizado em linha da responsabilidade de Bettencourt e Abad-Vidal (2014) e realizado no âmbito de um projeto de investigação, desenvolvido entre 2010 e 2014 (Bettencourt, Abad-Vidal \& Rodrigues, 2017), foi possível criar 45 entradas de arte rupestre pertencentes ao concelho de Viana do Castelo, distribuídos por 10 freguesias (Afife, Amonde, Areosa, Cardielos, Carreço, Freixieiro de Soutelo, Nogueira, Outeiro, Perre e Santa Maria Maior $)^{13}$. A estas há que juntar as gravuras rupestres inventariadas após esse período, que correspondem a mais 21, algumas delas inéditas (total de 9) e que se distribuem, igualmente, na margem esquerda do rio $\mathrm{Lima}^{14}$.

13. Algumas entradas correspondem a sítios já destruídos e, em dois casos, a observação noturna posterior, com luz artificial, demonstrou não se tratarem se gravados rupestres (Fornelos 2 e Pedra do Sol).

14. Disponíveis na base de dados que alimenta o CVARN mas ainda não disponibilizadas online. 
Se é verdade que o valor turístico de alguns destes sítios gravados é mínimo, há, contudo, alguns de extrema espetacularidade que interessa destacar e dar a conhecer de forma mais abrangente. Referimo-nos, por exemplo, a Lajedo 1, em Amonde (Bettencourt, Sá, Amorim, 2014) (Figura 4); Cais, em Freixieiro do Soutelo (Bettencourt, 2014a); conjunto da Ereira (inédito) e da Matança (Bettencourt, Silva, Simões, 2014), em Afife; Calvo 1, Fornelos (Bettencourt \& Simões, 2014a); Fraga/Laje do Bica (Baptista \& Magalhães, 1995; Bettencourt, 2009, p. 137-138, 155, 162), Moinhos do Marinheiro (inédita) e o conjunto da Sinadora, em Carreço (Bettencourt \& Amorim, 2014a, 2014b, 2014C, 2014d, 2014e, 2014f, 2014g) (Figura 5); Escampadinhos (Bettencourt et alii, 2014) (Figura 6) e Cabeço da Boucinha 1 (Bettencourt, 2014b), na Areosa; conjunto da Breia (com destaque para as Breias 1, 4, 5, 6 e 12), em Cardielos (Bettencourt, 2013; Bettencourt \& Santos-Estévez, 2018) (Figura 7) e Penedo da Moura 1 e 2, em Nogueira (Paço, 1942; Loureiro, 2006) (Figura 8).

Estes 11 sítios que correspondem, grosso modo, a 26 afloramentos gravados, foram selecionados por diversos motivos, a saber: número de motivos e sua visibilidade; diversidade de motivos; diversidade cronológica; diversidade de discursos interpretativos; aspectos litológicos e características da geoforma onde se gravaram; contexto físico; acessibilidades; bom estado de conservação e diversidade geográfica, possibilitando o acesso a vários discursos associados a estas materialidades e a várias áreas do Geoparque. Se Fornelos, Fraga do Bica, Moinhos do Marinheiro e o conjunto da Sinadora possibilitam a sua articulação com paisagens e geossítios litorais, Ereira, Matança, Calvo 1 e Escampadinhos inserem o visitante em pontos altos da serra de Santa Luzia, com particularidades geológicas distintas e com possibilidade da sua articulação com o Planalto Granítico das Chãs de Santa Luzia.

As gravuras de Lajedo 1 apresentam a especificidade de terem sido efetuadas num afloramentos de filito distribuído em bancadas (Bettencourt, Sá \& Amorim, 2014). Já as gravuras de Nogueira e Breia, localizadas na vertente nascente da serra de Perre e sobranceiras ao geossítio das Cristas Quartzíticas do Campo Mineiro de Folgadoiro-Verdes, disfrutam de contextos paisagísticos de grande interesse, por vezes com observação privilegiada para a serra de Arga ou para o vale do Lima (Figuras 4 e 8).
De salientar que a seleção destes sítios, gravados desde o Neolítico à Idade Média ou Moderna, isto é, desde os finais do 5\%/inícios do $4^{\circ}$ milénios AC até ao século XVI, teve em conta o facto de proporcionarem o conhecimento de diferentes formas de interação das comunidades do passado com o espaço em que se inseriram, materializando, igualmente, universos ideológicos distintos e proporcionando ao visitante experiências (na primeira pessoa) únicas da sacralidade do território ao longo do tempo (Figura 9).

Deve destacar-se que alguns destes sítios gravados já tinham sido considerados significativos para integrarem uma rota de arte rupestre da bacia do Lima, como é o caso de Penedo da Moura 1 e 2 (Nogueira), de Breia 1 e 2 (Cardielos), do Cabeço da Boucinha 1 e dos Escampadinhos (Areosa) (Sá, 2015, pp. 142-148).

Estes sítios apresentam algumas particularidades que condicionam a sua visibilidade a determinadas horas do dia, motivo pelo qual a sua valorização deve ser pensada de forma cuidada para não defraudar o visitante. Tal implica o desenvolvimento de diversas tarefas. Desde logo, e dada a natureza particular que facilmente afeta a observação destas gravuras, será imperativo produzir conteúdos de apoio gráfico e visual que permitam aos visitantes vislumbrar as gravuras. Não é de descartar, neste cenário, o recurso a materiais tridimensionais via fotogrametria, quer disponibilizados através de aplicações de telemóvel quer de modo a que possam chegar, numa perspetiva inclusiva, a pessoas com deficiências visuais ou motoras. Não menos importante, será a consecução de um centro interpretativo.

Bom exemplo de práticas sustentáveis futuras aplicadas ao registo arqueológico, é a implementação de fotogrametria para criar modelos $3 \mathrm{D}$ virtuais. O detalhe atingido por estes modelos, ainda que carentes de alguns pormenores (como, por exemplo, o facto de não detetarem as técnicas de gravação aplicadas aquando da execução das gravuras), mostra-se uma ferramenta de grande importância e de uso diversificado. Neste cenário, estes materiais não só servem a divulgação deste património em diferentes contextos, como se podem mostrar um efetivo e importante apoio a visitas-guiadas. Na verdade, o caráter diferenciador da visita-guiada a este tipo de recurso assenta, precisamente, na hora a que o mesmo é visitado. Como tal, é pertinente vincar que as melhores horas do 
dia para o fazer correspondem ao nascer e ao por do sol, com especial enfâse para as visitas noturnas, cuja experiência se mostra única. Contudo, tal implica uma concepção integrada, preocupada e válida ao nível das boas práticas, a par da necessidade, por parte dos guias, do acesso a conhecimentos especializados que permitam engrandecer a experiência dos visitantes. Isto obriga ao acesso a descrições concertadas entre arqueólogos e geólogos, destacando as particularidades litológicas de interesse para um público mais exigente.

\section{CONSIDERAÇÕES FINAIS}

Tendo como ponto de partida a seleção de recursos arqueológicos passíveis de se articularem com recursos naturais para, dessa forma, incrementar a oferta de produtos turísticos no território do GLVC, este trabalho demonstra que estes existem e que constituem uma mais valia que urge dinamizar. Embora outras combinações possam ser possíveis, os recursos arqueológicos escolhidos para demonstrar a sua possibilidade de articulação com a geologia incidiram em três áreas: a produção de sal, a exploração mineira de estanho, ouro e volfrâmio e a arte rupestre.

Se para a produção de sal há já alguns itinerários que combinam recursos naturais e arqueológicos (conforme são exemplo os geossítios de Canto Marinho e da Ínsuas do Lima), para a exploração mineira poderá ser ponderada a articulação entre as cortas desativadas das minas do Folgadoiro e as gravuras rupestres da Breia, do Penedo da Moura 1 e 2 e do Lajedo 1. Quanto à arte rupestre há apenas um afloramento gravado valorizado no âmbito de um geossítio - o de Fornelos. Ainda assim, a sua placa informativa apresenta-se manifestamente incompleta em termos do diálogo passível de estabelecer entreosmotivosgravadoseageoforma (Bettencourt et alii, 2017), além de estar mal localizada. Também se deve destacar que no seio deste geossítio há o conjunto de gravuras rupestres da Sinadora, passível, igualmente, de destaque, quer pela sua diversidade geomorfológica em relação a Fornelos quer pela gramática estilística que apresenta e pelos diferentes universos ideológicos que materializa.

Para tentar inverter esta situação, há algumas ações que poderão produzir certos resultados, muitas das quais estão já a ser implementadas como parte de iniciativas planeadas. São exemplo a percep- ção, por parte da gestão do GLVC, da necessidade de criar discursos concertados; a criação de alguns modelos tridimensionais fotogramétricos a partir de fotografia digital, tanto para sítios naturais como arqueológicos, que possam, depois, ser canalizados para conteúdos interpretativos; o desenvolvimento de novo projetos de investigação relacionados com a arte rupestre da região, em diálogo com a arqueoastronomia, proporcionando novos discursos interpretativos; o estudo relativo às percepções que os habitantes locais e a generalidade da população vianense tem sobre o recurso arte rupestre, através da implementação de um questionário posteriormente tratado com recurso a Statistical Package for the Social Sciences (SPSS); a realização de visitas guiadas aos locais e aproximação aos stakeholders para promover o conhecimento e vincar a importância local deste património; a criação do Núcleo Museológico do Património Mineiro de Arga e Lima, uma porta do GLVC dedicada à mineração que vem valorizar a herança cultural local. Conscientes que a educação patrimonial é um longo caminho a trilhar, a população mais nova, os gestores, os decisores políticos, os profissionais de turismo e os visitantes do futuro devem estar informados. Mas o processo de consolidação educativo tem, obrigatoriamente, que acontecer a diferentes escalas. É indispensável que as comunidades locais saibam o que têm e lhe atribuam valor identitário. Só dessa forma é possível passar para outros níveis de projeção, sejam eles regionais, nacionais ou internacionais. Este é o primeiro passo para assegurar etapas futuras de valorização dentro de uma lógica de sustentabilidade social, económica e ambiental. Não deverão ser alheias, a esta realidade, políticas concertadas entre diferentes atores locais, cabendo o envolvimento entre associações, residentes e empresários do sector turístico sob a mediação inteligente do executivo municipal.

\section{APOIOS}

Trabalho realizado no âmbito da Dissertação de Mestrado em Turismo, Inovação e Desenvolvimento subordinada ao tema A arte rupestre como potenciadora de novas experiências culturais no âmbito do Geoparque Litoral de Viana do Castelo (Noroeste de Portugal), em curso na Escola Superior de Gestão e Tecnologia do Instituto Politécnico de Viana do Castelo, e do projeto Rota de Arte Rupestre do 
Noroeste Português: um projeto de Turismo Cultural, coordenado por Ana M.S. Bettencourt.

\section{BIBLIOGRAFIA}

ALMEIDA, Carlos A.B. (2005) - A exploração do sal na costa portuguesa a Norte do Rio Ave: da Antiguidade Clássica à Baixa Idade Média. In AMORIM, Inês, ed. - Seminário Internacional sobre o Sal Português. Porto: Instituto de História Moderna, pp. 139-170.

ALVES, António M.C. (1996) - Causas e processos da dinâmica sedimentary na evolução actual do litoral do Alto Minho. Braga: Universidade do Minho (Doutoramento).

ALVES, Lourenço (1989) - A Comenda de Santa Maria de Carreço (monografia). carreço: Junta de Freguesia de Carreço.

ALVES, Raquel C. (2014) - Contribuição para um sistema de gestão integrada de sítios mineiros do NW de Portugal. Braga: Universidade do Minho (Tese de Doutoramento).

BAPTISTA, Ivone (1986) - Arte Rupestre de Carreço. Boletim Cultural Alto Minho. Viana do Castelo. 3, pp. 116 -128.

BAPTISTA, Ivone; Magalhães, Carmo (1985) - Arte rupestre de Carreço, Centro de Estudos Regionais. Boletim Cultural Alto Minho. Viana do Castelo. 2, pp. 92-102.

BARRANHA, Helena (2016) - Património cultural: conceitos e critérios fundamentais. Lisboa: IST Press/ICOMOS Portugal.

BETTENCOURT, Ana M.S. (20og) - Entre os montes e as águas: ensaio sobre a percepção dos limites na pré-história da faixa costeira entre o Minho e o Lima (NW português). In BETTENCOURT, Ana M.S.; ALVES, Lara B., eds. - Dos montes, das pedras e das águas: formas de interacção com o espaço natural da pré-história à actualidade. Braga: CITCEM, pp. 131-162.

BETTENCOURT, Ana M.S. (2013) - Gravuras rupestres da Breia, Cardielos, Viana do Castelo. In BETTENCOURT Ana M.S., ed. - A Pré-História do Noroeste Português. Braga/Tomar: CEIPHAR/CITCEM, pp. 207-215.

BETTENCOURT, Ana M.S. (2014a) - Cais. In Bettencourt, Ana M.S.; Abad-Vidal, Emilio, eds. - CVARN-Corpus Virtual de Arte Rupestre do Noroeste Português (www.cvarn.org).

BETTENCOURT, Ana M.S. (2014b) - Cabeço da Boucinha 1. In Ana M.S. Bettencourt, Emilio Abad-Vidal, eds. -CVARN-Corpus Virtual de Arte Rupestre do Noroeste Português (www.cvarn.org).

BETTENCOURT, Ana M.S. (2019) - Equídeos nos Montes do Noroeste português. Narrativas míticas gravadas nas rochas. In PEREIRA, Andreia, ed. - O garrano: contributos da investigação histórico-arqueológica, antropológica e equestre para a sua valorização. Viana do Castelo: Município de Viana do Castelo, pp. 135-148.
BETTENCOURT, Ana M.S.; AMORIM, Maria João (2014) - Sinadora I In BETTENCOURT, Ana M.S.; ABAD-VIDAL, Emílio, eds. - CVARN-Corpus Virtual de Arte Rupestre do Noroeste Português (www.cvarn.org).

BETTENCOURT, Ana M.S.; AMORIM, Maria João (2014c) - Sinadora 2. In BETTENCOURT, Ana M.S.; ABAD-VIDAL, Emilio, eds. - CVARN-Corpus Virtual de Arte Rupestre do Noroeste Português (www.cvarn.org).

BETTENCOURT, Ana M.S.; AMORIM, Maria João (2014d) - Sinadora 3. In BETTENCOURT, Ana M.S.; ABAD-VIDAL, Emilio, eds. - CVARN-Corpus Virtual de Arte Rupestre do Noroeste Português (www.cvarn.org).

BETTENCOURT, Ana M.S.; AMORIM, Maria João (2014e) - Sinadora 4 In BETTENCOURT, Ana M.S.; ABAD-VIDAL, Emílio, eds. - CVARN-Corpus Virtual de Arte Rupestre do Noroeste Português (www.cvarn.org).

BETTENCOURT, A.M.S.; AMORIM, Maria J. (2014f ) Sinadora 5. In BETTENCOURT, Ana M.S.; ABAD-VIDAL, Emílio, eds. - CVARN-Corpus Virtual de Arte Rupestre do Noroeste Português (www.cvarn.org).

BETTENCOURT, A.M.S., AMORIM, Maria J. (2014g) Sinadora 6. In BETTENCOURT, Ana M.S.; ABAD-VIDAL, Emílio, eds. - CVARN-Corpus Virtual de Arte Rupestre do Noroeste Português (www.cvarn.org).

BETTENCOURT, Ana M.S.; ABAD-VIDAL, Emílio (2014) - Corpus Virtual de Arte Rupestre do Noroeste Português CVARN (www.cvarn.org).

BETTENCOURT, A.M.S.; SIMÕES, Pedro P. (2014) - Calvo 1. In Bettencourt, Ana M.S.; Abad-Vidal, Emílio, eds. CVARN-Corpus Virtual de Arte Rupestre do Noroeste Português (www.cvarn.org).

BETTENCOURT, A.M.S.; SANTOS-ESTÉVEZ, Manuel (2018) - A geografia mágica do Monte de São Silvestre, em Viana do Castelo, através da arte rupestre. Braga: Lab2PT.

BETTENCOURT, Ana M.S.; SÁ, Edite; AMORIM, Diana (2014) - Lajedo 1. In Bettencourt, Ana M.S.; Abad-Vidal, Emílio, eds. - CVARN-Corpus Virtual de Arte Rupestre do Noroeste Português (www.cvarn.org).

BETTENCOURT, Ana M.S.; SILVA, Isabel S.; SIMÕES, Pedro P. (2014) - Matança/Suvidade. In Bettencourt, Ana M.S.; Abad-Vidal, Emílio, eds. - CVARN-Corpus Virtual de Arte Rupestre do Noroeste Português (www.cvarn.org).

BETTENCOURT, Ana M.S.; ABAD-VIDAL, Emilio; RODRIGUES, Alda (2017) - CVARN - Rock Art Virtual Corpus of North-Western Portugal. A multimedia tool to investigate and describe Post-Palaeolithic rock art. In BETTENCOURT, A.M.S., SANTOS-ESTÉVEZ, M.; SAMPAIO, Hugo A.; CARDOSO, Daniela, eds.-Recorded Places, Experienced Places. The Holocene rock art of the Iberian Atlantic north-west. British Archaeological Reports - International Series, 2878. Oxford: BAR Publishing, pp. 19-26. 
BETTENCOURT, A.M.S.; COMENDADOR REY, Beatriz; SIMÕES, Pedro P.; ALVES, Maria I.C. (2014) - O depósito de machados do Bronze Final de Cobidalto, Areosa (Viana do Castelo). Novos dados para a sua contextualização e interpretação. In BETTENCOURT, Ana M.S., COMENDADOR REY, Beatriz; SAMPAIO, Hugo; SÁ, Edite, eds. - Corpos e Metais na Fachada Atlântica da Ibéria. Do Neolítico à Idade do Bronze. Braga: APEQ, CITCEM, pp. 131-142.

BETTENCOURT, Ana M.S.; AMORIM, Maria João; MENDES, Sílvia; NOGUEIRA, Cristina; SIMÕES, Pedro P. (2014) - Escampadinhos. In Ana M.S. Bettencourt; Emilio Abad-Vidal, eds. - CVARN-Corpus Virtual de Arte Rupestre do Noroeste Português (www.cvarn.org).

BETTENCOURT, A.M.S.; LUZ, Sara; SIMÕES, Pedro P.; ALVES, Maria I.C.; ABAD-VIDAL, Emilio (no prelo) Bronze Age sea salt production in Northwest Iberian Peninsula. In MARCIGNY, Cyril; MORDANT Claude, eds. - Bronze 2019: 20 ans de recherches, Dijon: Suppléments au Bulletin de l'APRAB.

BETTENCOURT, Ana M.S.; LUZ, Sara; OLIVEIRA, Nuno; SIMÕES, Pedro P.; ALVES, Maria Isabel C.; ABAD-VIDAL, Emilio (2020) - Produção de sal marinho na Idade do Bronze do Noroeste português. Alguns dados para uma reflexão. In Actas do III Congresso da Associação de Arqueólogos Portuguese, Porto: Faculdade de Letras da Universidade do Porto.

BROCHADO, Cláudio (2004) - Povoamento Tardo-romano e Altimedieval na bacia terminal do rio Lima (séculos IV-XI). Porto: Faculdade de Letras da Universidade do Porto (Tese de Mestrado).

CARDOSO, Fonseca (1897) - Penedo com insculturas, nos arredores de Viana do Castelo. O Archeologo Português. Lisboa. 3, pp. 170-172.

CARVALHIDO, Ricardo (2014) - Processo de classificação dos 5 monumentos naturais locais de Viana do Castelo: Anexo II - Memória Descritiva. Viana do Castelo: Câmara Municipal de Viana do Castelo.

CARVAlHIDO, Ricardo; PEREIRA, D.; CUNHA, Pedro (2017) - Geossítios do Geoparque Litoral de Viana do Castelo. Atas do $8^{\circ}$ Congresso Nacional de Geomorfologia: Geomorfologia 2017. Porto: APGeom, pp. 27-29.

COSTA, Miguel; MACHADO, Jorge; LOPES, Hugo; ALMEIDA, Tiago (2012) - Pias salineiras da praia do Canto Marinho. Inventário Arqueológico. Cadernos Vianenses. Viana do Castelo. 46, pp. 95-111.

COSTA, Miguel; ALMEIDA, Tiago; MACHADO, Jorge (2019) - A exploração de sal na Proto-História. O exemplo de Viana do Castelo, comunicação apresentada nos Encontros monográficos co património Cultural in situ. A prudoción de sal en época romana no sur de Galicia e Norte de Portugal, A Guarda, March 29th, 2019. Disponível em https:// www.youtube.com/watch?v=leDyyodniAM [consultado em: $1 / 4 / 2020]$.
DAVIDSON, James M.; BRANDON, Jamie C. (2012) Descenent community partenering, the politics of time, and the logistics of reality: Tales from North American, African diáspora, archaeology. In SKEATES, Robin; MCDAVID, Carol \& CARMAN, John, eds. - The Oxford Handbook of Public Archaeology. Oxford: Oxford University Press, pp. 605-628.

ENSEÑAT-SOBERANIS, Fernando; FRAUSTO-MARTÍNEZ, Oscar; GÁNDARA-VÀSQUEZ, Manuel (2019) A visitor flow management process for touristified archaeological sites. Journal of Heritage Tourism. London. 14:4, pp. 340-357.

FERNANDES, Almeida (1994) - Meadela Histórica. Paróquia de Santa Cristina da Meadela. Viana do Castelo: Ed. autor.

FERNANDES, João O.; BETTENCOURT, Ana M.S.; COMENDADOR REY, Beatriz; ALVES, Maria I.C. (2011) - O depósito metálico da Bandeira, Viana do Castelo (Norte de Portugal) no contexto dos depósitos metálicos do Bronze Médio do curso inferior da bacia do rio Lima. Estudos do Quaternário. Porto.7, pp. 33-39.

FUNDAÇÃO GIL EANNES (2007) - História do Navio. Disponível em https://www.fundacaogileannes.pt/engine.php? cat $=10 \&$ sheet $=3$ [consultado em: $13 / 7 / 2020]$.

GLOBAL GEOPARK NETWORK (2020) - What is a UNESCO Global Geopark? Disponível em http://www. globalgeopark.org/aboutGGN/6398.htm [consultado em: 10/6/2020].

HODDER, Ian; HUTSON, Scott (2003) - Reading the past: current approaches to interpretation in Archaeology ( $3^{\underline{a}}$ ed.). Cambridge: Cambridge University Press.

ICOMOS 1990 - Charter for the Protection and Management of the Archaeological Heritage, International Committee on Archaeological Heritage Management Information, 3, pp. 20-24.

LANHAS, Fernando (1969) - As Gravuras Rupestres de Montedor. Revista de Etnografia. Porto. 13(2), pp. 367-386.

LIMA, Maria F.D. (2006) - Caracterização e estratégias de valorização sustentável de ocorrências geológicas com importância patrimonial. Braga: Universidade do Minho (Tese de Doutoramento).

LOUREIRO, Luís F. (2006) - O santuário rupestre do Penedo da Moura (Nogueira, Viana do Castelo. Almadan Online. Almada. 14: pp.11-16.

MAGALHÃES, Marisa C. (2016) - O Calcolítico e a Idade do Bronze na bacia do rio Neiva, NW de Portugal. Braga: Universidade do Minho (Tese de Mestrado).

MANTEIGA BREA, Alexandre; BETTENCOURT, Ana M.S.; COMENDADOR REY, Beatriz (2014) - El depósito de Pereiras Pequenas en Vila de Punhe, Viana do Castelo (Norte de Portugal). Una revisión del contexto deposicional. Gallaecia. Santiago de Compostela. 33, pp. 121-136. 
MATEUS, J. (2003) - Arqueologia ambiental sob a tutela da Cultura - uma experiência com 20 anos, um desafio para a nossa arqueologia. In MATEUS, José E.; MORENO-GARCíA, Marta; FARIA, António M., eds. - Paleoecologia humana e arqueociências um programa multidisciplinar para a arqueologia sob a tutela da cultura. Lisboa: Instituto Português de Arqueologia (IPA), Ministério da Cultura, pp. 21-32.

MOREIRA, José (2018) - Podomorfos na Fachada Ocidental do Noroeste de Portugal, entre os Rios Douro e Minho. Braga: Universidade do Minho (Tese de Mestrado).

MOREIRA, Manuel A.F. (1981) - As Arrugiae da Época Romana no Vale de Rio Tinto. Actas do I Colóquio Galaico Minhoto, Ponte de Lima (vol. II). Ponte de Lima. Instituto Cultural Galaico-Minhoto, pp. 395-423.

NUNES, J.P.A. (2010) - O Estado Novo e o Volfrâmio (19331947). Coimbra: Imprensa da Universidade de Coimbra.

OLIVEIRA, Nuno (2019) - The Iron Age settlement of Terronha (Viana do Castelo, Northwestern Portugal): ananlysis of ceramic and lithic materials in context. Heritage. Basel. 1:2, pp. 65-71.

OLIVEIRA, Nuno; BETTENCOURT, Ana M.S. (2020) - O povoado de Santo António (Afife, Viana do Castelo), na Idade do Bronze Final. Antrope. Tomar. 13 (no prelo).

PAÇO, Afonso do (1942) - Gravuras rupestres de Outeiro e Carreço (Viana do Castelo). O Instituto. Coimbra. 1oo, pp. 271-274.

SÁ, Sofia (2015) - Turismo Arqueológico: um Projeto de Valorização da Arte Rupestre do Vale do Lima. Braga: Universidade do Minho (Tese de Mestrado).

SANTOS, Ana C. (2013) - Gravuras rupestres da Laje da Churra. In BETTENCOURT, Ana M.S., ed. - A Pré-História do Noroeste Português (volume 2). Braga/Tomar: CEIPHAR/CITCEM, pp. 196-20o.

SANTOS, Ana C. (2014) - A Lage da Churra (Carreço, Viana

do Castelo). Estudo Monográfico de um Lugar Gravado. Braga: Universidade do Minho (Tese de Mestrado).

SANTOS-ESTÉVEZ, Manuel; BETTENCOURT, Ana M.S. (2017) - O conjunto de gravuras rupestres de Santo Adrião (Caminha, Portugal). Embarcações, armas, cavalos e ex-votos. In ARNAUD, José M.; MARTINS, Andrea, eds. Arqueologia em Portugal 2017-Estado da Questão. Lisboa: Associação de Arqueólogos Portugueses, pp. 1055-1070.

SANTOS-ESTÉVEZ, Manuel; BETTENCOURT, Ana M.S.; SAMPAIO, Hugo A.; CARDOSO, Daniela; BROCHADO, Cláudio; FERREIRA, Gonçalo (2017) - Shape and meaning. Engraved weapons as materialisations of the Calcolithic/ Early Bronze Age cosmogony. In BETTENCOURT, Ana M.S.; SANTOS-ESTÉVEZ, Manuel; SAMPAIO, Hugo A.; CARDOSO, Daniela, eds. - Recorded Places, Experienced Places. The Holocene Rock Art of the Iberia Atlantic Northwest, Oxford: BAR Publishing, pp. 151-165.
SILVA, António (2008)-Vivre au-delà du fleuve de l'oubli; portrait de la communauté villageoise du Castro do Vieito au moment de l'intégration du NO de la péninsule ibérique dans l'orbis Romanum: estuaire du Rio Lima, NO du Portugal, Coimbra: Universidade de Coimbra (Tese de Doutoramento).

SILVA, António (2014a) - Piotinha 1. In A.M.S. Bettencourt; E. Abad-Vidal (eds.) CVARN-Corpus Virtual de Arte Rupestre do Noroeste Português.

SILVA, António (2014b) - Piotinha 2. In A.M.S. Bettencourt; E. Abad-Vidal (eds.) CVARN-Corpus Virtual de Arte Rupestre do Noroeste Português (www.cvarn.org).

SOLSONA MONZONÍS, Javier; RICO CÁNOVAS, Elisa (2014) - Patrimonio arqueológico in situ: desarrollo y turismo. In Vives-Ferrándiz Sánchez, Jaime; Ferrer García, Carlos, ed. - El pasado en su lugar: patrimonio arqueológico, desarrollo y turismo. Valência: Museo de Prehistória de Valência, pp. 29-62.

TEIXEIRA, Carlos; MEDEIROS, Artur C.; COELHO, António V.P. (1972) - Carta geológica de Portugal na escala de 1/50 ooo: notícia explicativa da folha 5-A, Viana do Castelo. Lisboa: Serviços Geológicos do Exército.

THOMAS, Suzie (2017) - Community Archaeology. In Moshenska, Gabrie, ed. - Key Concepts in Public Archaeology. London: University College London Press.

TIMOTHY, Dallen J. (2011) - Cultural Heritage and Tourism: An Introduction. Bristol: Channel View Publications.

TIMOTHY, Dallen J.; Tahan, Lina G. (2020) - Archaeology and Tourism. Consuming, Managing and Protecting the Human Past. In TIMOTHY, Dallen J.; TAHAN, Lina G., eds. - Archaeology and Tourism: Touring the Past. Bristol: Channel View Publications, pp. 10-44.

UNESCO (2001) - Universal Declaration on Cultural Diversity. United Nations Educational, Scientific and Cultural Organization Disponível em: http://portal.unesco.org/ en/ev.php-URL_ID=13179\&URL_DO=DO_TOPIC\&URL_ $\mathrm{SECTION=201.html} \mathrm{[consultado} \mathrm{em} \mathrm{4/6/2020].}$

UNESCO (2006) - Tourism, Culture and Sustainable Development. Paris: UNESCO.

UNWTO (2020) - Sustainable tourism development guidelines. United Nations World Tourism Organization. Disponível em: https://www.unwto.org/sustainable-development. [consultado a $11 / 6 / 2020]$.

VIANA, Abel (1960) - Insculturas Rupestres do Alto Minho (Lanhelas e Carreço, Viana do Castelo Portugal). Boletim de la Comisión de Monumentos Históricos y Artísticos de Orense. Ourense. 22(1-4), pp. 209-321.

WALKER, Cameron (2005) - Archaeological Tourism: looking for answers along Mexico's Maya Reviera. National Association for the Practice of Anthropology Bulletin. Washington, D.C. 23:(1), pp. 60-76. 
WATERTON, Emma;-SMITH, Laurajane (2009) - There is no such thing as heritage. In WATERTON, Emma; SMITH, Laurajane, eds. - Taking Archaeology Out of Heritage. Newcastle-upon-Tyre: Cambridge Scholars, pp. 10-27.

WHC (2020) - Sustainable Tourism. UNESCO World Heritage and Sustainable Tourism Programme. World Heritage Committee. Disponível em: https://whc.unesco.org/en/ tourism/ [consultado em 10/6/2020].

YAMAMOTO, Yoko Sugiura; NIETO HERNÁNDEZ, Rubén (2013) - Una reflexión sobre la preservación del patrimonio arqueológico: el caso de los sitios de escala menor en el Estado de México. Anales de Antropología. Ciudad de México. 48:2, pp.75-95.
ZBYSZWESKI, Georges; FERREIRA, Octávio V. (1955) - Sur un plaque anthropomorphe en cuivre dans la mine d'étain de "Folgadoura". Comunicações dos Serviços Geológicos de Portugal, 36, pp. 49-5o.

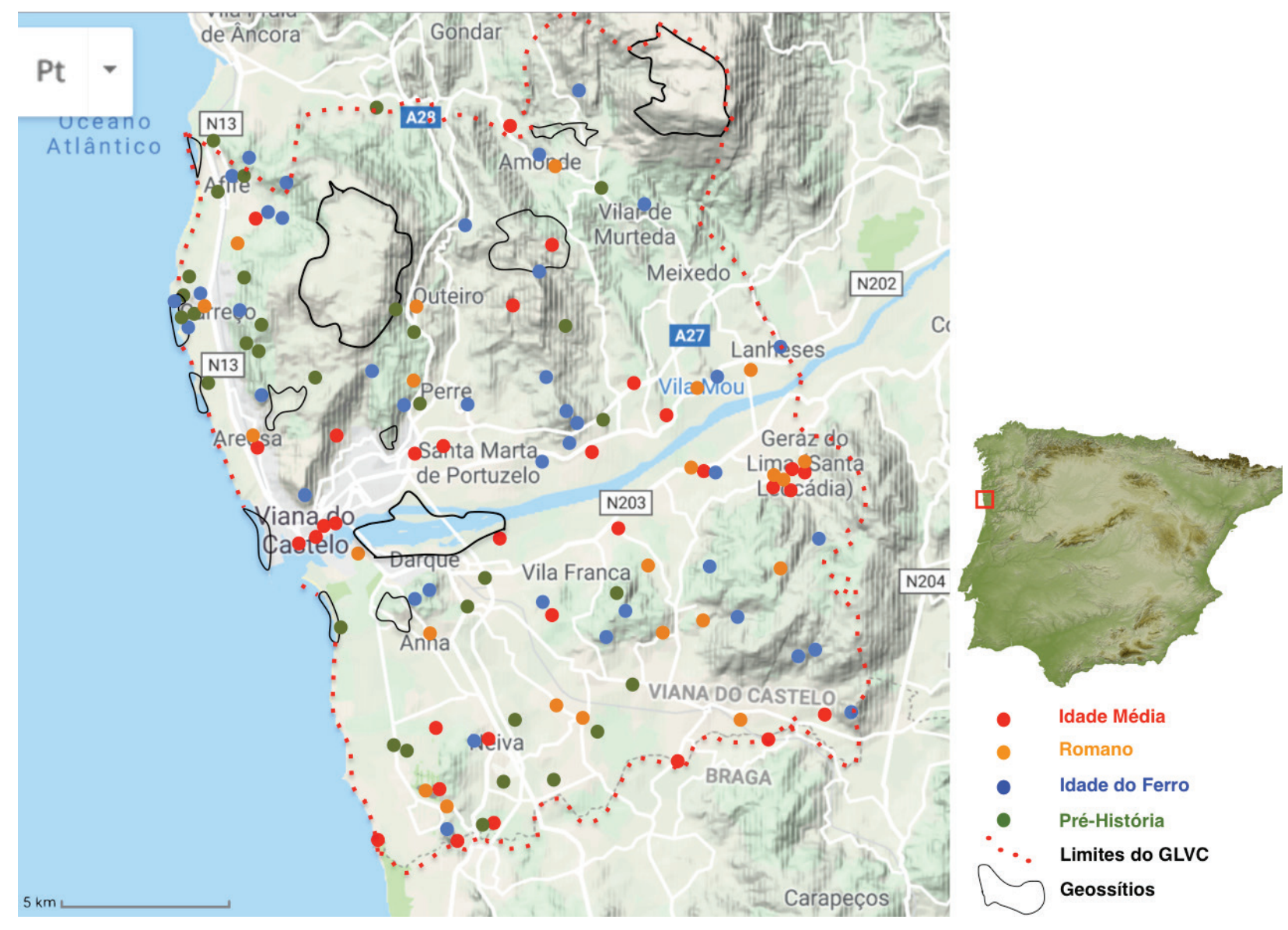

Figura 1 - Mapa de sítios arqueológicos com limites e geossítios do GLVC classificados; Fonte: adaptado de http://www.cmviana-castelo.pt/pt/roteiro-arqueologico sobre base do Google Maps. 

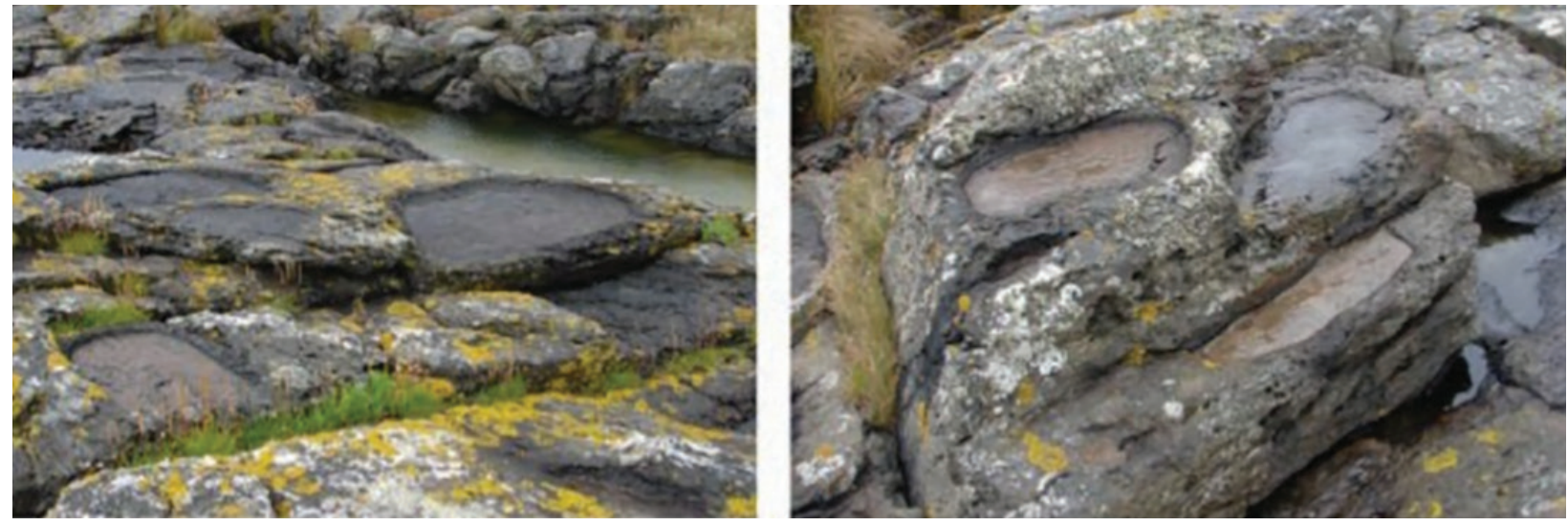

Figura 2 - Alguns exemplares das pias salineiras, de origem antrópica, que integram o sítio de Canto Marinho.
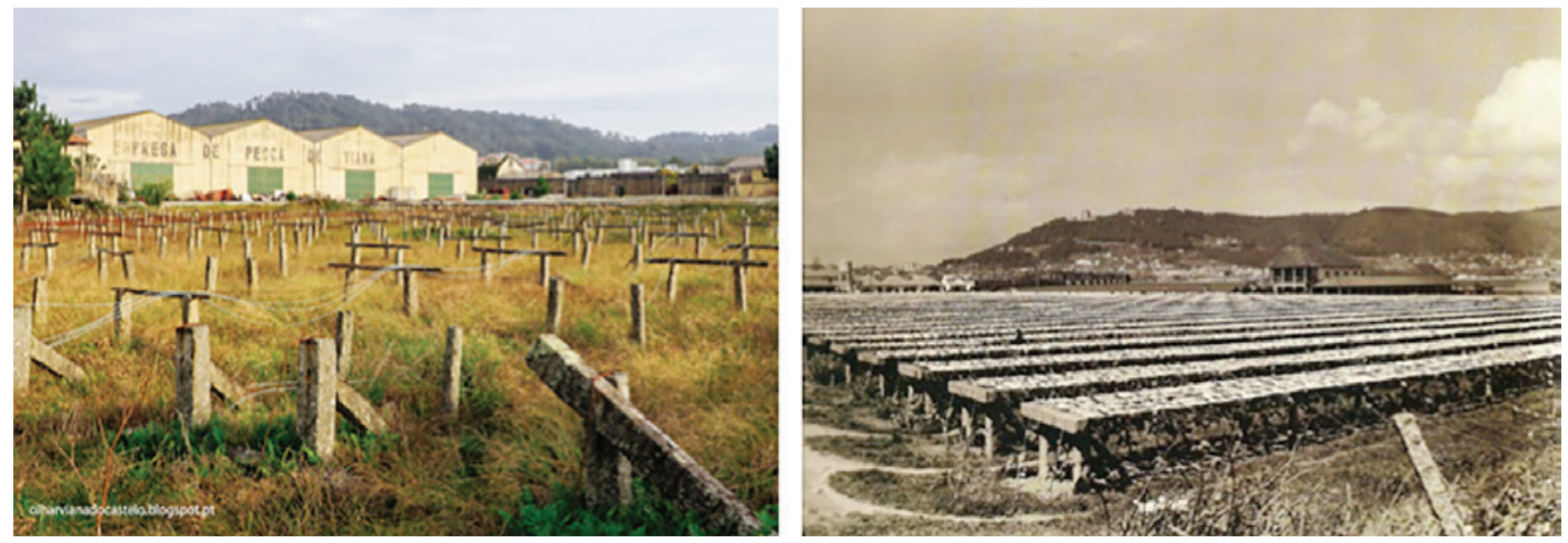

Figura 3 - Complexo de seca do bacalhau do Cais Novo, Darque, Viana do Castelo (à esquerda) e fotografia da atividade aí realizada durante o século XX; Fonte: https://bloguedominho.blogs.sapo.pt/1554662.html.

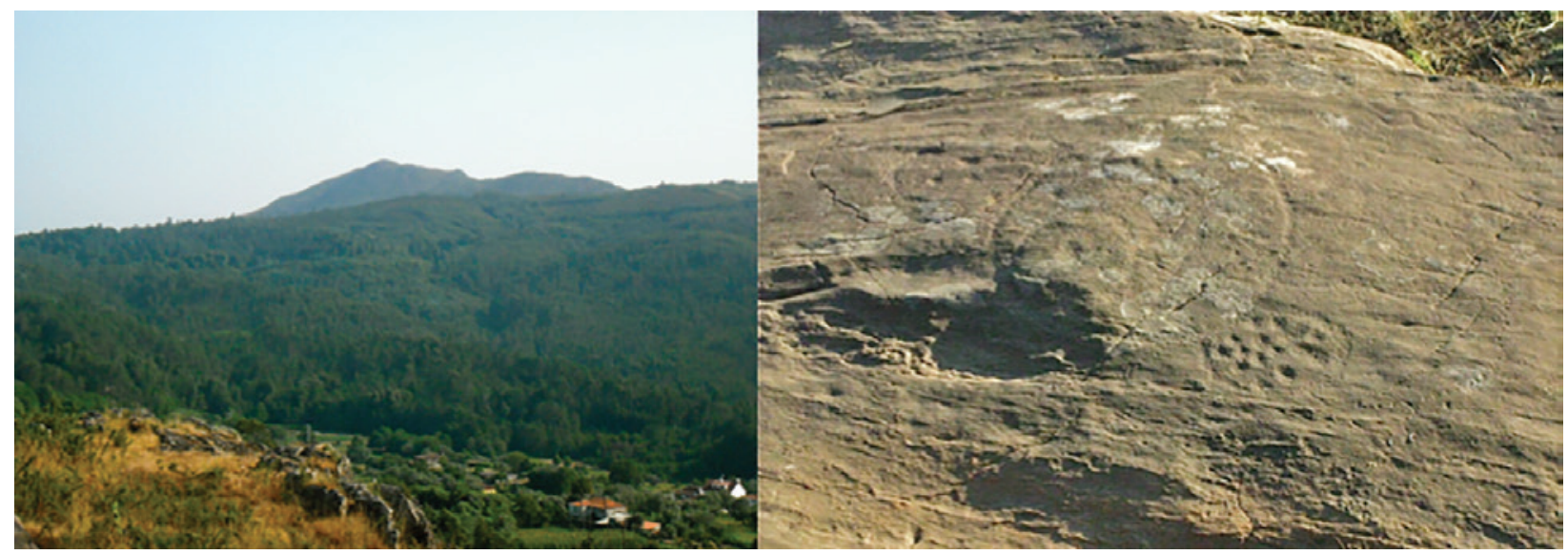

Figura 4 - Lajedo 1 com vista para o topo da Serra de Santa Luzia; Fonte: A.M.S. Bettencourt e Bettencourt, Sá \& Amorim, 2014, p. 2, Fig. 1. 


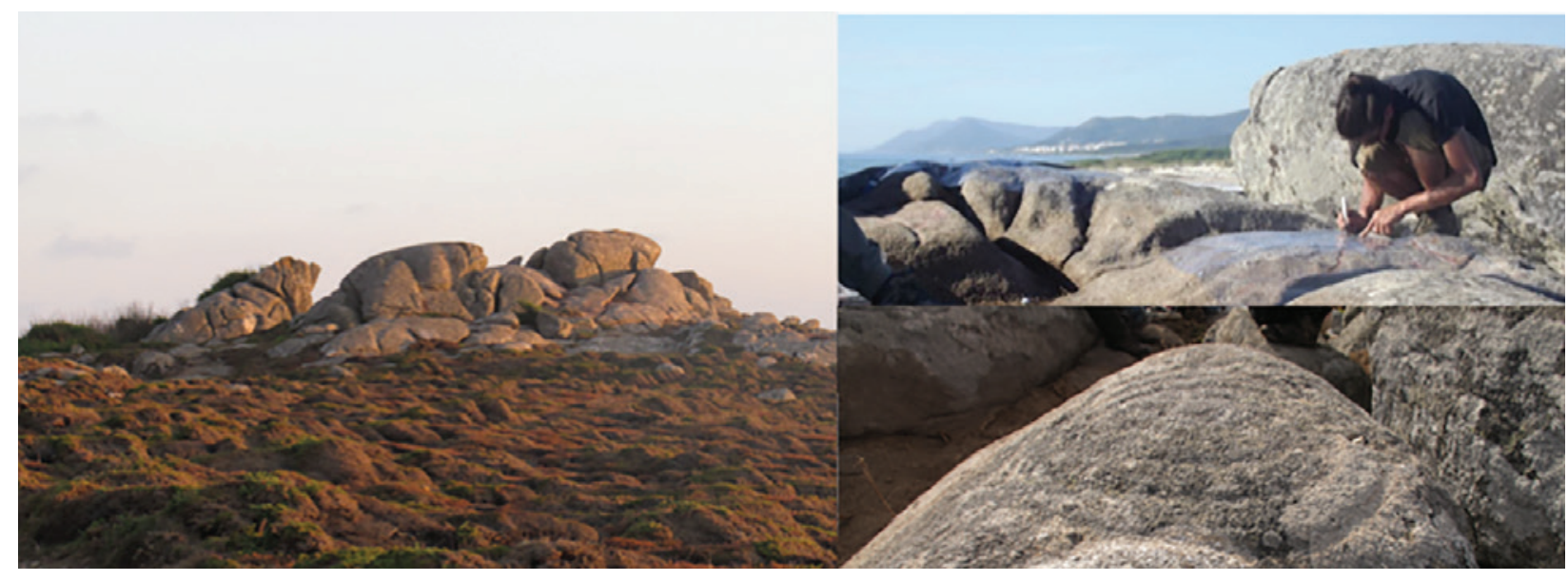

Figura 5 - Afloramentos da Sinadora (esquerda) e pormenor das suas gravuras e da vista obtida a partir do-local; Fonte: A.M. S. Bettencourt.
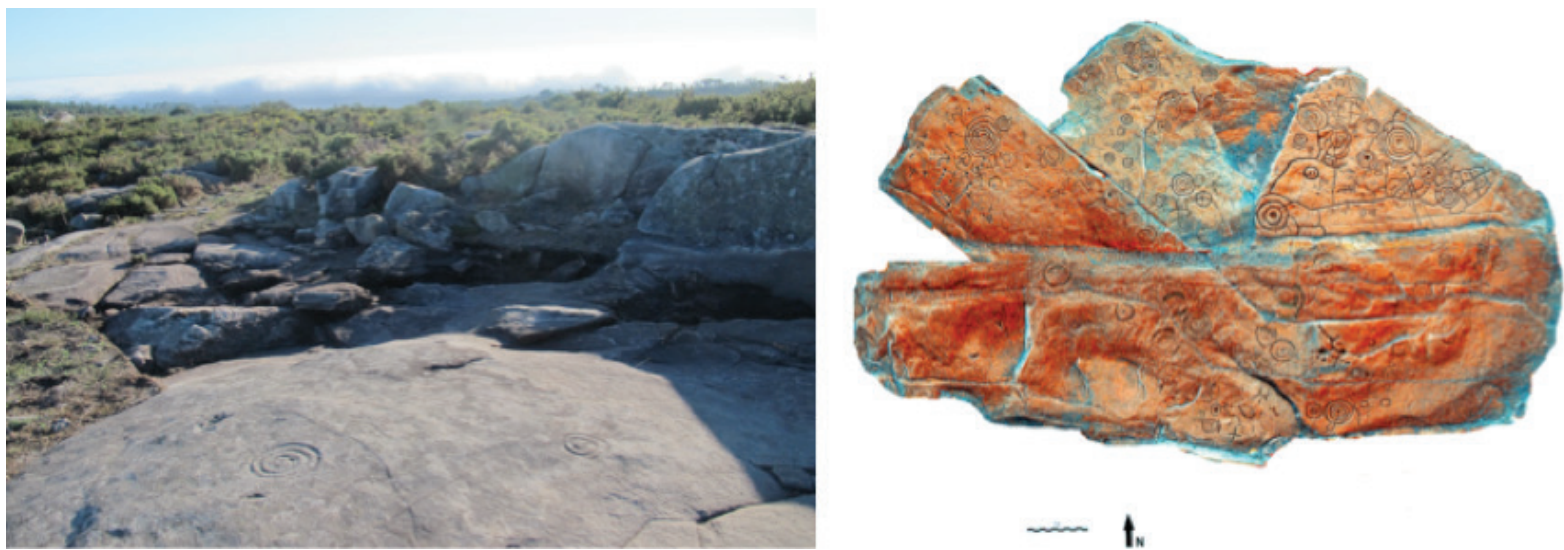

tw

Figura 6 - Afloramentos dos Escampadinhos (esquerda) (fonte: A.M.S. Bettencourt) e fotogrametria da Breia 1 (direita); Fonte: adaptado de Bettencourt \& Santos-Estévez, 2018, p. 34, Fig. 8.

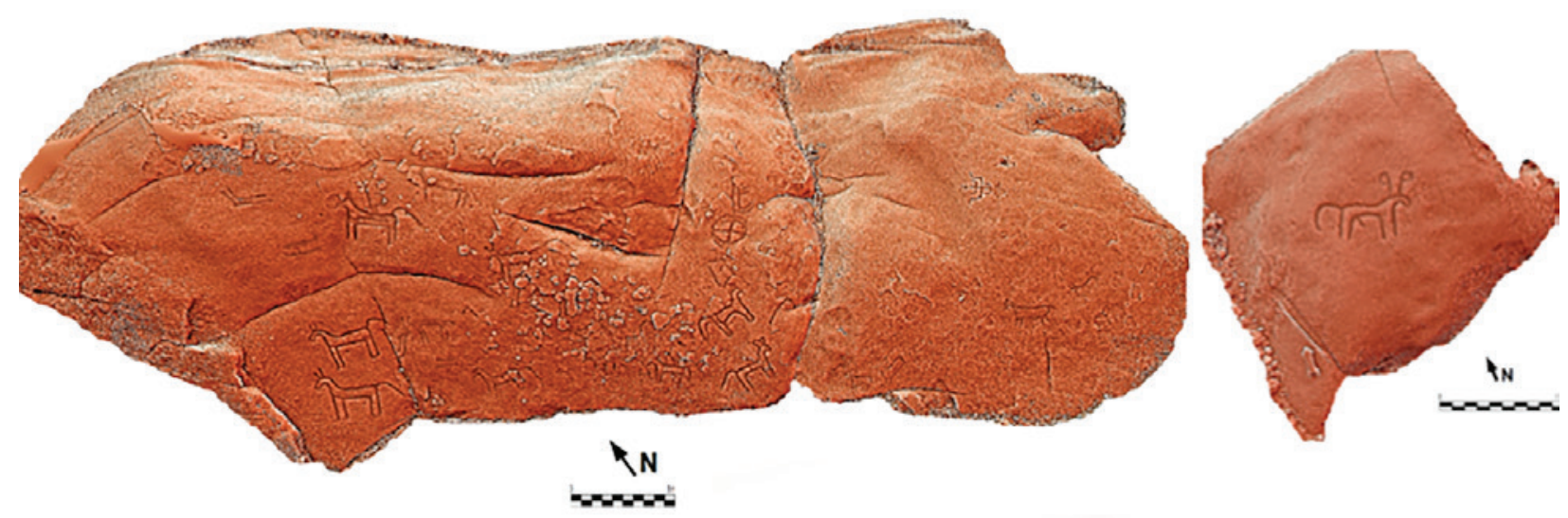

Figura 7 - Breia 5 (esquerda) e Breia 6 (direita); Fonte: Bettencourt \& Santos-Estévez, 2018, p. 59, Fig. 26, p. 62 , Fig. 28. 


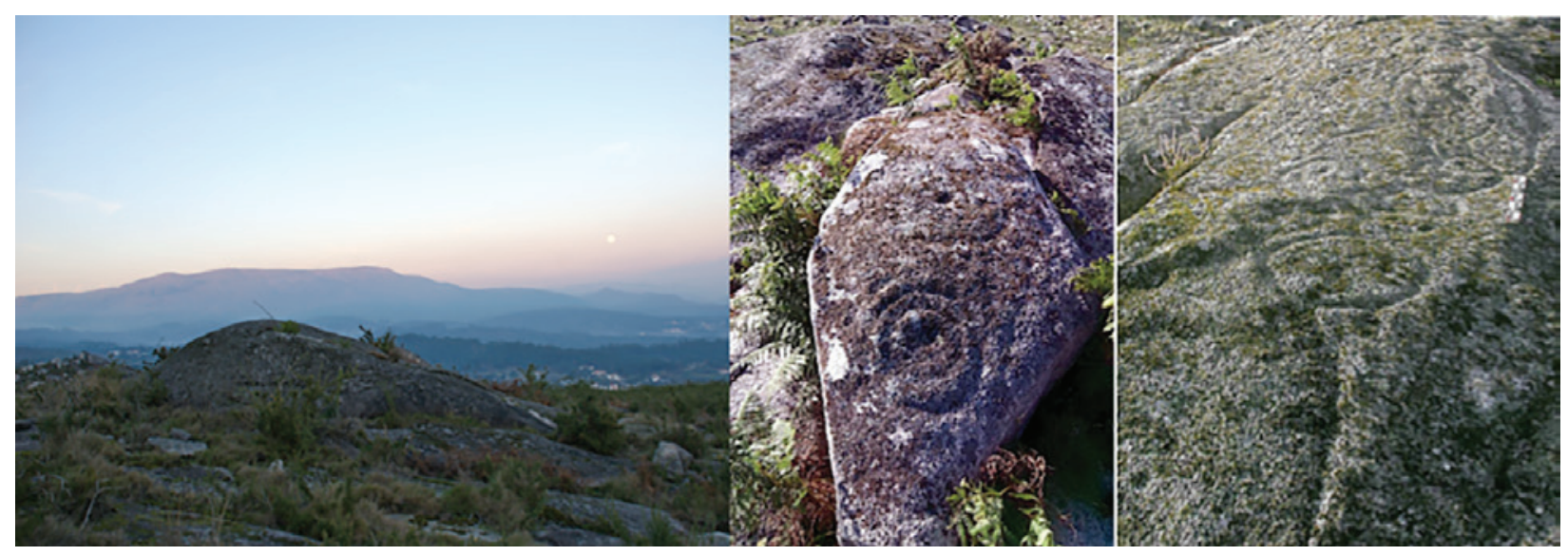

Figura 8 - Sítios de arte rupestre de Penedo da Moura 1 e 2 e vista para a serra de Arga; Fonte: A.M.S. Bettencourt.

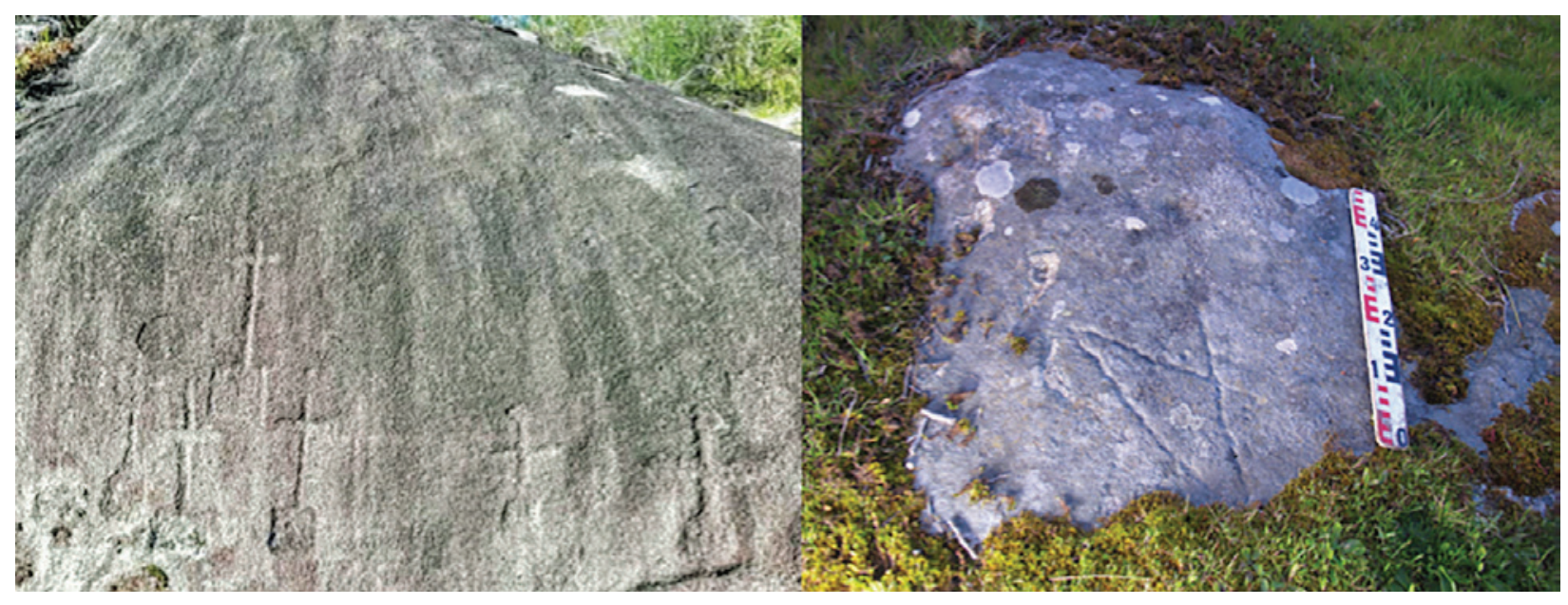

Figura 9- Gravuras de iconografia cristã: Breia 12 com cruzes latinas e gregas, algumas com bases quadrangulares e circulares, figurando cruzeiros (esquerda), e pentagrama dos Moinhos do Marinheiro (direita); Fonte: fonte figura da esquerda: José Alvarez Alonso; fonte figura da direita: A.M.S. Bettencourt. 



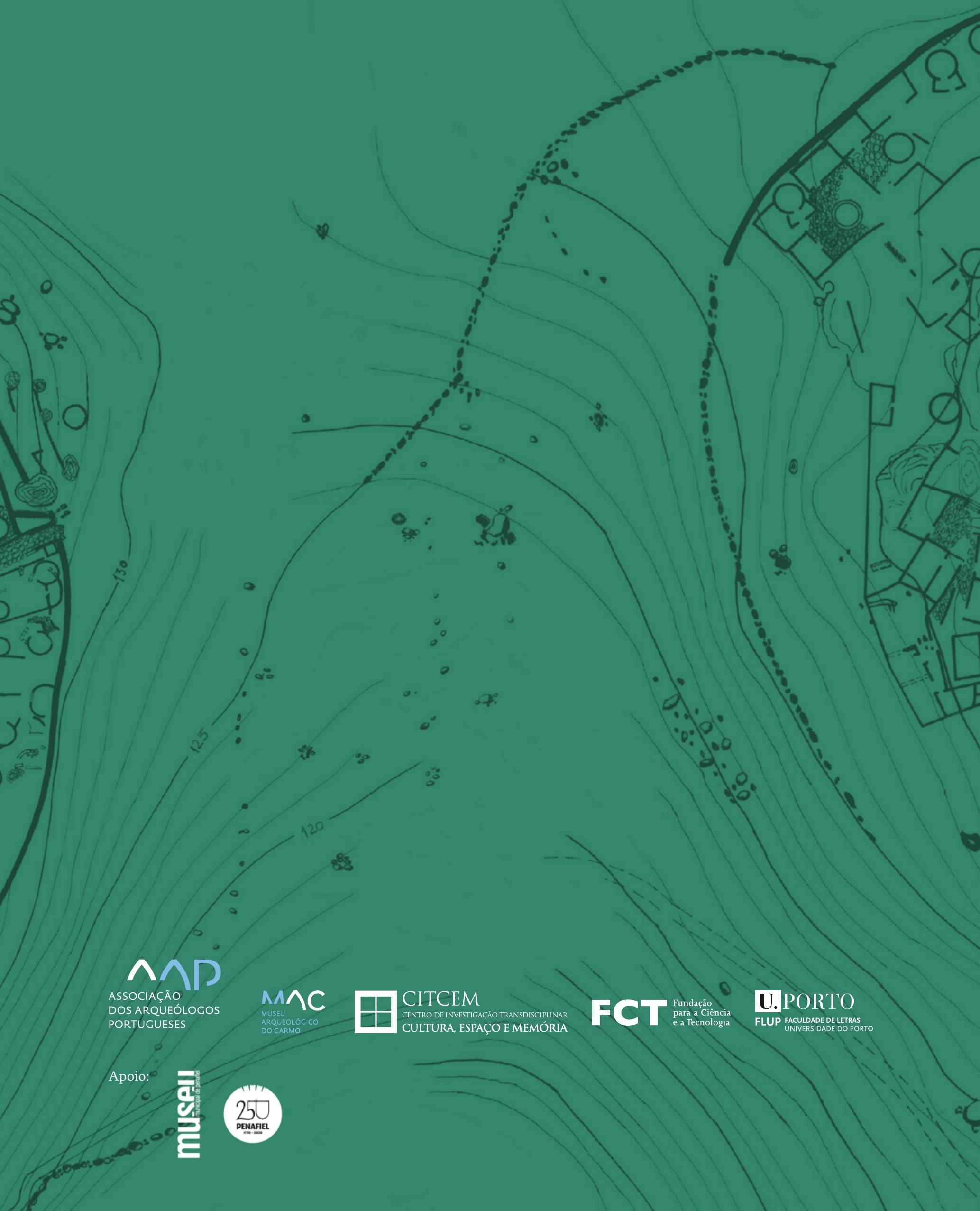

